OPEN ACCESS

Edited by:

Kerstin Feistel,

University of Hohenheim, Germany

Reviewed by:

Kris Vleminckx,

Ghent University, Belgium

Sally Ann Moody,

George Washington University,

United States

*Correspondence:

Béatrice C. Durand

beatrice.durand@sorbonne-

universite.fr

Specialty section:

This article was submitted to

Morphogenesis and Patterning,

a section of the journal

Frontiers in Cell and Developmental

Biology

Received: 28 September 2021

Accepted: 28 October 2021

Published: 24 November 2021

Citation:

Bou-Rouphael J and Durand BC (2021) T-Cell Factors as

Transcriptional Inhibitors: Activities and

Regulations in Vertebrate

Head Development.

Front. Cell Dev. Biol. 9:784998.

doi: 10.3389/fcell.2021.784998

\section{T-Cell Factors as Transcriptional Inhibitors: Activities and Regulations in Vertebrate Head Development}

\author{
Johnny Bou-Rouphael and Béatrice C. Durand * \\ Sorbonne Université, CNRS UMR7622, IBPS Developmental Biology Laboratory, Campus Pierre et Marie Curie, Paris, France
}

Since its first discovery in the late 90s, Wnt canonical signaling has been demonstrated to affect a large variety of neural developmental processes, including, but not limited to, embryonic axis formation, neural proliferation, fate determination, and maintenance of neural stem cells. For decades, studies have focused on the mechanisms controlling the activity of $\beta$-catenin, the sole mediator of Wnt transcriptional response. More recently, the spotlight of research is directed towards the last cascade component, the T-cell factor (TCF)/Lymphoid-Enhancer binding Factor (LEF), and more specifically, the TCF/LEFmediated switch from transcriptional activation to repression, which in both embryonic blastomeres and mouse embryonic stem cells pushes the balance from pluri/multipotency towards differentiation. It has been long known that Groucho/Transducin-Like Enhancer of split (Gro/TLE) is the main co-repressor partner of TCF/LEF. More recently, other TCF/LEFinteracting partners have been identified, including the pro-neural BarH-Like 2 (BARHL2), which belongs to the evolutionary highly conserved family of homeodomain-containing transcription factors. This review describes the activities and regulatory modes of TCF/LEF as transcriptional repressors, with a specific focus on the functions of Barh/2 in vertebrate brain development. Specific attention is given to the transcriptional events leading to formation of the Organizer, as well as the roles and regulations of $\mathrm{Wnt} / \beta$-catenin pathway in growth of the caudal forebrain. We present TCF/LEF activities in both embryonic and neural stem cells and discuss how alterations of this pathway could lead to tumors.

Keywords: Tcf/Lef, transcription, signalization, stem cells, Barhl, forebrain, Wnt

\section{INTRODUCTION}

Understanding how the vertebrate nervous system emerges from a homogeneous layer of neuroepithelial cells, the neural plate, has long been a subject of intense fascination. Fatemapping experiments performed at the end of the 20th century demonstrated that the primordia of the forebrain, midbrain, hindbrain, and spinal cord are all already established along the antero-posterior (AP) axis when the neural plate emerges. These studies revealed that a construction blueprint of the neural organization, and specifically that of the forebrain, is set up during gastrulation (reviewed in Wilson and Houart, 2004; Hoch et al., 2009; Andoniadou and Martinez-Barbera, 2013). In 1924, Hans Spemann and Hilde Mangold discovered that the dorsal lip of a newt blastopore, when grafted into the ventral part of a host embryo, is able to induce a secondary axis containing a complete nervous system (Spemann and Mangold, 1924). This small group of specialized cells, referred to as the "Organizer," emerges during embryonic development at gastrulation, acts as a local source of secreted signaling factors and drives both neural induction and 
TABLE 1 | TCF/LEF, Gro/TLE and BARHL homologues across species.

\begin{tabular}{|c|c|c|c|c|c|}
\hline & Drosophila melanogaster & Caenorhabditis elegans & Xenopus laevis & Mus musculus & Homo sapiens \\
\hline \multirow[t]{4}{*}{ TCF/LEF } & Pan & POP1 & Tcf7 (Tcf1) & TCF7 (TCF1) & TCF7 (TCF1) \\
\hline & & & Tcf7l1 (Tcf3) & TCF7I1 (TCF3) TCF7I2 (TCF4) & TCF7I1 (TCF3) TCF7I2 (TCF4) \\
\hline & & & Tcf7l2 (Tcf4) & LEF1 (LEF1) & LEF1 (LEF1) \\
\hline & & & Lef1 (Lef1) & & \\
\hline Gro/TLE & Gro & UNC-37 & Gro1-4 & GRG1-4, GRG5 & TLE1-4 \\
\hline BARHL1 & BarH2 & СЕНЗО & Barhl1 & BARHL1 (MBH2) & BARHL1 \\
\hline BARHL2 & BarH1 & & Barhl2 & BARHL2 (MBH1) & BARHL2 \\
\hline
\end{tabular}

Invertebrate have a single T-cell factor/Lymphoid enhancer-binding factor (TCF/LEF): Pangolin (Pan) in flies and POP1 in worm. Vertebrate have four TCF/LEF known as TCF7, TCF7l1, TCF7I2 and LEF1, previously termed TCF1, TCF3, TCF4 and LEF1 respectively. Drosophila Groucho (Gro) and C. elegans UNC-37 corepressors have four vertebrate orthologs: Gro1-4 in frogs, Groucho-related gene (GRG1-4) in mice, and Transducin-like enhancer of split (TLE1-4) in human. In mice, GRG5 acts as a dominant negative. The homeobox-containing proteins $\mathrm{BarH} 1$ and BarH2 have been first identified in Drosophila. Homologues have been described in vertebrate, named BarH-like or BARHL. In mice, BARHL have been previously referred to as mammalian BarH (MBH1 and $\mathrm{MBH} 2)$. C. elegans Bar homeodomain gene (CEH30) represents the homologue of Drosophila BarH1 and BarH2 and their vertebrate counterparts.

patterning of the prospective neuroepithelium and thereby of the developing head (reviewed in De Robertis et al., 2000; Niehrs, 2004; Kiecker and Lumsden, 2012; Anderson and Stern, 2016). Since this discovery, an organizing center has been found in other model organisms: Hensen's node in the chick, the node in the mouse and the shield in zebrafish, and the capacity of the blastopore-associated tissue to induce naïve cells to form a fully developed twin embryo was found conserved in nonbilaterian metazoan species (Kraus et al., 2016).

Initial regionalization of the neural plate relies on the synergistic action of at least five major signaling pathways that convey spatial and temporal information to naïve cells, consequently inducing developmental programs that drive their behavior (reviewed in Stern, 2002; Wessely and De Robertis, 2002; Ozair et al., 2013). Amongst the cell-to-cell signaling pathways coordinating development, one of the most conserved in the animal kingdom is the $\mathrm{Wnt} / \beta$-catenin, or canonical pathway. During emergence of the central nervous system, Wnt/ $\beta$-catenin acts in a coordinated manner with Sonic HedgeHog (Shh), Notch, Transforming Growth Factor (TGF- $\beta$ ), and Fibroblast Growth Factor (FGF) pathways and contributes to neural patterning, proliferation, and fate determination. Notably, the $\mathrm{Wnt} / \beta$-catenin machinery drives the transcriptional events leading to the induction of the Organizer, and thereby formation of the embryonic axes. Its participation is also crucial in Neural Stem Cell (NSC) maintenance and self-renewal. Not surprisingly, dysregulation of $\mathrm{Wnt} / \beta$-catenin signaling is linked to serious brain developmental defects, including cancer (reviewed in Hoppler and Moon, 2014; Brafman and Willert, 2017; Nusse and Clevers, 2017).

After four decades of intense research following the initial discovery of Wnt signals (Nusse and Varmus, 1982, reviewed in Nusse and Varmus, 2012), 19 ligands have been characterized in mammals, together with two families of receptors comprising 10 Frizzled receptors, and two Low-Density Lipoprotein (LDL) receptor-related proteins (LRP5/6) (reviewed in MacDonald et al., 2009; Niehrs, 2012). Despite this complexity, the large majority of $\mathrm{Wnt} / \beta$-catenin transcriptional targets are regulated by T-Cell Factor/Lymphoid Enhancer-binding Factor (TCF/LEF) transcription factors (TF). Loss of function analysis performed in invertebrate such as the nematode Caenorhabditis elegans ( $C$. elegans) and in flies, where a single TCF/LEF has been characterized, provided evidence that TCF/LEF act through a transcriptional switch, which either activates or represses Wnt/ $\beta$-catenin target genes' expression. This feature has been further validated in vertebrate, whose genome contains four TCF/LEF members: TCF1, TCF3, TCF4, and LEF1. In this review, the vertebrate TCF/LEF members will be referred to as TCF7 (previously TCF1), TCF7L1 (TCF3), TCF7L2 (TCF4) and LEF1 following the Human Genome Organization (HUGO) nomenclature (Table 1). As will be discussed below, some of the vertebrate TCF/LEF have a more specialized function compared to their invertebrate counterparts.

In most of the species investigated so far, TCF/LEF activate transcription in Wnt-stimulated cells by interacting with the sole transcriptional activator $\beta$-catenin (Schuijers et al., 2014), but TCF/LEF can recruit other partners to the transcriptional activating machinery. A massive effort has been deployed to understand TCF/ $\beta$-catenin transcriptional modes of activation. Very elegant and detailed accounts of the current models supporting Wnt-dependent transcriptional activation events have been published recently (reviewed in van Amerongen and Nusse, 2009; Wiese et al., 2018; Söderholm and Cantù, 2021).

In the absence of Wnt ligands, TCF/LEF interact with repressor partners to inhibit Wnt target genes' expression. The best-characterized co-repressor partner is Groucho/ Transducin-Like Enhancer of split (Gro/TLE) (Brantjes, 2001). Under certain conditions, Gro/TLE can recruit Histone Deacetylases (Hdac) to the complex, a chromatin remodeling enzyme which removes acetyl groups from the $\mathrm{N}$-terminal lysine residues of the core histones, inducing gene expression silencing through chromatin condensation (Sekiya and Zaret, 2007). Recent evidence reveals a role for the homeodomain (HD)-containing TF BarH-Like Homeobox-2 (BARHL2) in enhancing TCF/Gro repressive activity in vitro and in vivo and preventing the $\beta$-catenin-mediated transactivation of TCF/LEF target genes (Sena et al., 2019). These data highlight a novel mechanism regulating Wnt/ $\beta$-catenin transcriptional response, probably involving the chromatin modifier Hdac1. Studies from hemichordates to vertebrate, which are evolutionarily more than 500 million years apart, have revealed that, despite the differences between species, they all carry two Barhl genes: Barhl1 and Barhl2, each 


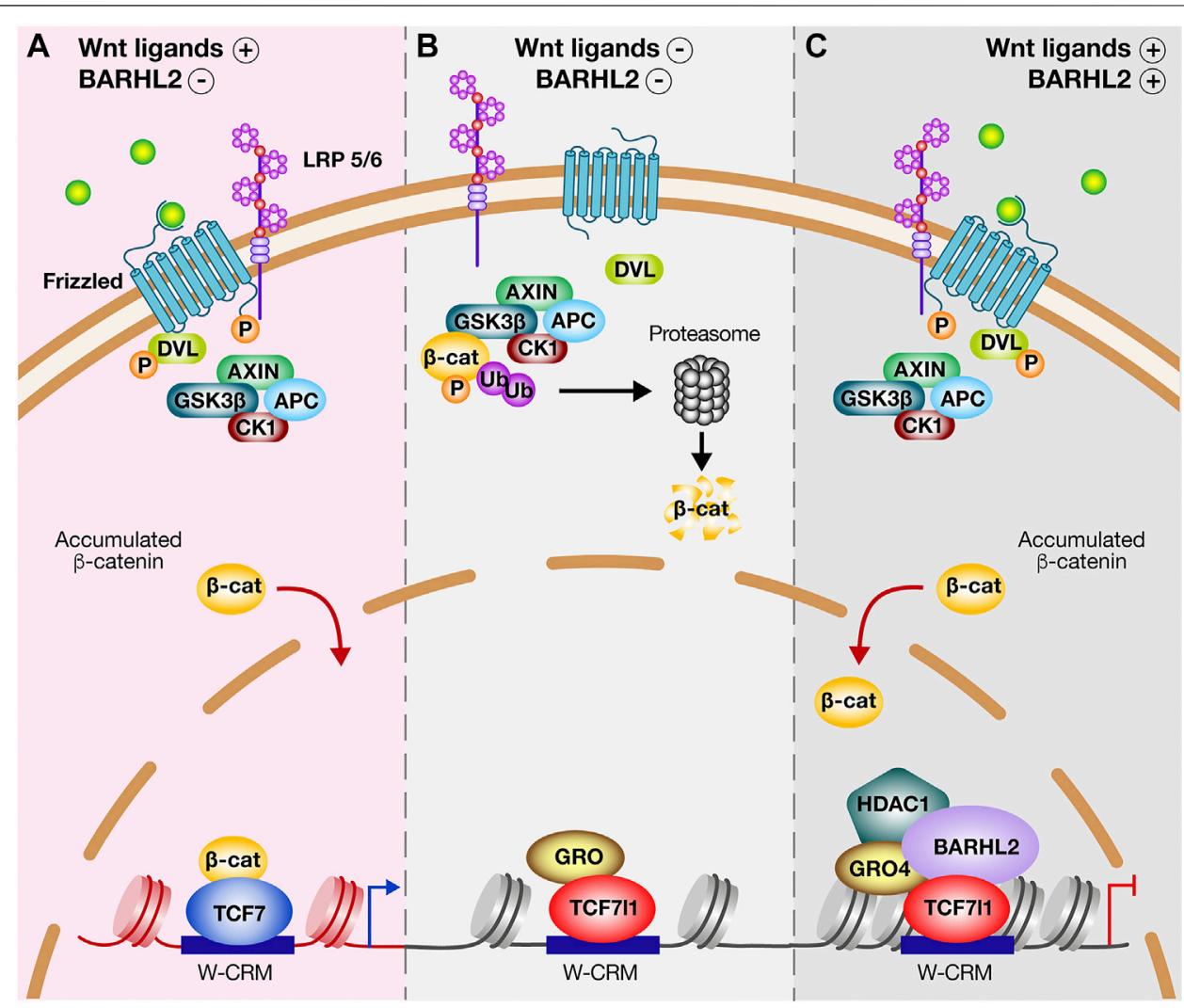

FIGURE 1 | BARHL2 regulatory mode of Wnt canonical pathway. (A) Upon Wnt binding to Frizzled (Frz) and Low-Density Lipoprotein Receptor-related Protein (LRP) family of receptors 5 and 6, the multiprotein destruction complex components (Scaffold protein AXIN, Adenomatous Polyposis Coli (APC) tumour suppressor protein, Casein Kinase 1 (CK1), and Glycogen Synthase kinase $3 \beta$ (Gsk3 $\beta)$ ) are recruited to the receptor complex, where they are internalized. Frz binds to Disheveled (DVL) keeping AXIN and Gsk3 $\beta$ inactive. $\beta$-catenin ( $\beta$-cat) escapes degradation, accumulates and translocates into the nucleus, where it binds to activating T-Cell Factors such as TCF7. TCF7 bound on Wnt-Cis regulatory motif (W-CRM) acts as transcriptional activator. (B) In the absence of Wnt ligands, the destruction complex is activated. Gsk3 $\beta$ and CK1 phosphorylate $\beta$-cat, allowing for its recognition by the E3 ubiquitin ligase (Ub) and targeting it for ubiquitination and proteasomal degradation. In the nucleus, the co-repressive factor Groucho (Gro) binds through its Glutamine (Q)-rich domain to TCF7I1 inducing a transcriptional repression. (C) In Wnt-stimulated cells, the presence of BARHL2 inhibits the cell response to $\beta$-cat. BARHL2 interacts with the Tryptophan/Aspartic acid (WD)-rich domains of Gro4 via its Engrailed Homology 1 (EH1) motifs and interacts with TCF7I1. The domain mediating BARHL2-TCF7I1 interaction is unknown. BARHL2 stabilizes the TCF7I1/Gro4 complex, reinforcing transcriptional repression of Wnt target genes. The complex containing TCF7I1, Gro, and BARHL2 could recruit histone deacetylases (HDAC), which induces inherited epigenetic modifications.

having a remarkably evolutionarily conserved structure, distribution, and function. The spectrum of TCF/Gro transcriptional targets is large. Both TCF/LEF and Gro/TLE proteins interact with other TFs, and are targets for developmental signals, which influence their activities. The extent and importance of TCF repressive roles, and their regulatory modes during embryogenesis are neither fully grasped, nor fully understood.

In this review, we present the activities and regulatory modes of TCF as transcriptional repressors with a focus on the developmental roles of Barhl2. Specific attention is given to the transcriptional events leading to the formation of the Organizer, as well as the roles and regulations of the Wnt/ $\beta$-catenin pathway in the growth of the caudal forebrain. We present core activities of TCF/LEF in Embryonic Stem Cells (ESCs) self-renewal and pluripotency, and maintenance of NSCs, as well as their identified deregulations and the emergence of cancer.

\section{Transcriptional Regulation of Wnt Target Genes by the TCF/LEF Factors - A Focus on the TCF-Mediated Transcriptional Repression}

TCF/LEF proteins are the major mediators of Wnt-responsive gene transcription in the nucleus. In the absence of Wnt ligands, $\beta$-catenin is phosphorylated by the destruction complex containing Glycogen Synthase Kinase $3 \beta$ (GSK3 $\beta$ ), Casein Kinase 1 (CK1), Adenomatous Polyposis Coli (APC) tumour suppressor protein, and Axin. Phosphorylated $\beta$-catenin is targeted towards ubiquitination and further proteasomemediated degradation. In the nucleus, inhibitory TCF/LEF members are bound on Wnt Cis-Regulary-Motifs (W-CRM), interact with co-repressors such as Gro/TLE proteins, and act as transcriptional repressors. Conversely, in Wnt-stimulated cells, the destruction complex is inhibited leading to the cytoplasmic accumulation of $\beta$-catenin and further nuclear translocation. 


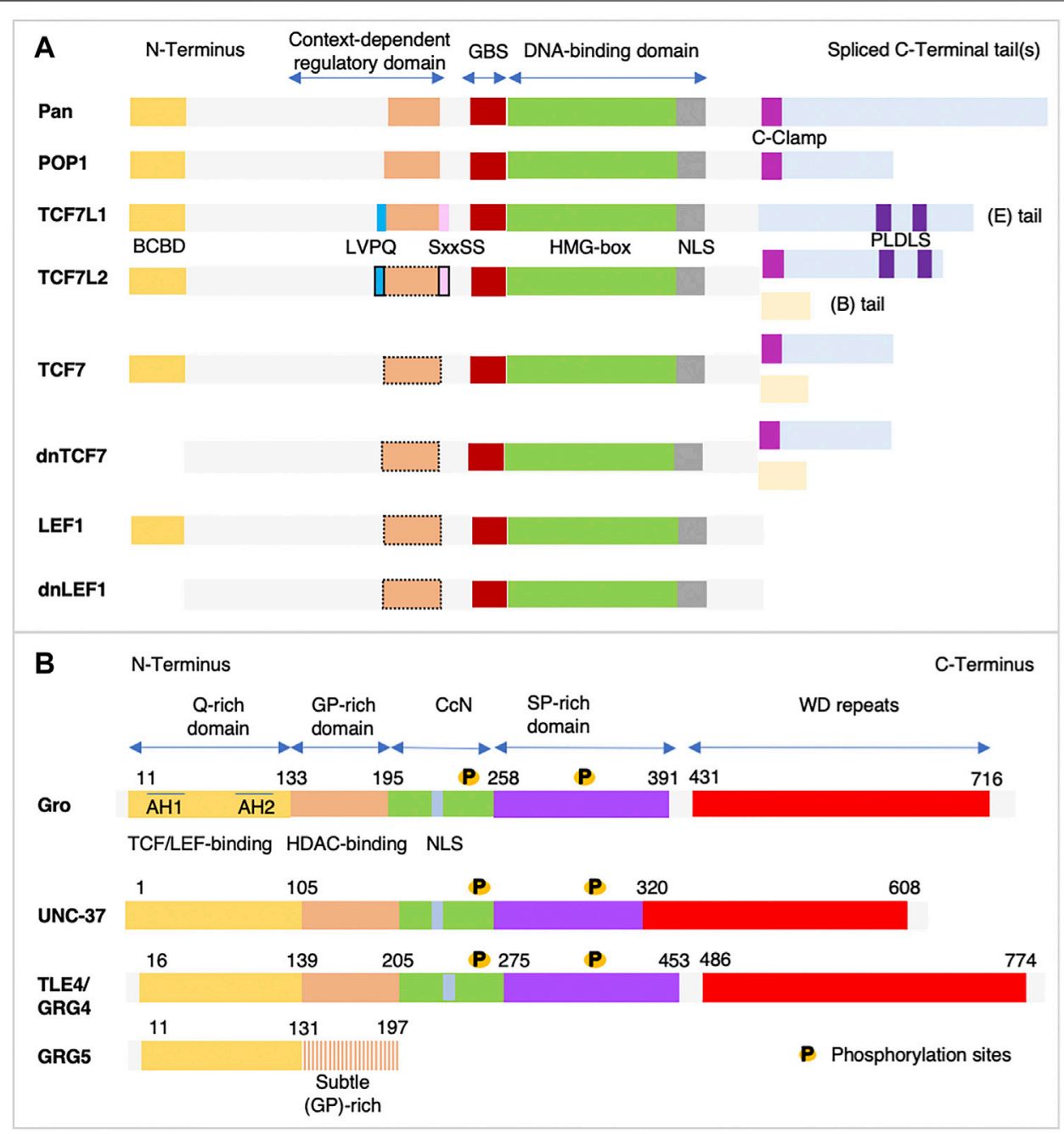

FIGURE 2 | (A) Structural organization of the TCF/LEF proteins. Invertebrate (Pangolin (Pan) in Drosophila, POP1 in C. elegans), and vertebrate T-Cell Factor/ Lymphoid Enhancer Factor (TCF/LEF) proteins share several highly conserved domains: the N-terminal $\beta$-catenin-binding domain (BCBD) shown in dark yellow, the DNA-binding domain which contains a High-Mobility Group box (HMG-box) shown in green and a Nuclear Localization Signal (NLS) shown in grey. The DNA-binding domain is preceded by a less well-defined binding sequence for the Groucho/Transducin-like enhancer of split (Gro/TLE) (Gro-binding sequence, GBS) shown in dark red. Several protein isoforms are encoded by the genome of vertebrate, except for TCF711. The Context-dependent Regulatory Domain (CRD) is less conserved and is encoded by three exons. One of them, indicated in orange, can be alternatively spliced in all vertebrate isoforms except TCF7L1. Black dotted lines indicate possible alternative splicing. In TCF711 and in TCF712, this CRD domain is flanked by two small motifs LVPQ shown in blue at its N-terminal end, and SxxSS shown in pink at its $C$ terminal end, which contribute to TCF7L1/2 repressive activity. Whereas these two motifs are always present in TCF7l1, in TCF7/2 they can be alternatively spliced. Less conservation is found in the C-terminal tail, as it is highly variable in length. The long (E) tails shown in light blue contain additional regulatory domains: the C-clamp DNA-binding motif shown in violet, present in most invertebrate and in the vertebrate TCF7I2 and TCF7, and two C-terminal-binding protein (CtBP) motifs (PLDLS) shown in dark blue, found in TCF711 and TCF7I2. Isoforms of TCF7 and LEF1 expressed from alternative promoters and encoding proteins lacking BCBD behave as dominant-negative. Alternative splicing also generates proteins with short (B) tails shown in light yellow. LEF1 isoform lacks the C-terminal tail. This scheme is inspired by (Hoppler and Waterman, 2014). (B) Schematic representations of Gro/TLE proteins functional domains. Sequence comparison of the Drosophila Groucho (Gro) (NP_001247309.1), human TLE4 (NP_001269677.1), mouse Groucho-related gene 4 (GRG4) (NP_001289876.1), and C. elegans UNC-37 (NP_491932.1) reveals the presence of five domains. The two most highly conserved domains are: 1- the amino-terminal glutamine-rich (Q) domain shown in dark yellow that contains two amphipathic a-helices (AH1 and AH2) and is required for Gro/TLE oligomerization, and interactions with other proteins including the TCF/LEF proteins; and 2- the Tryptophane/Aspartic acid (WD)-repeats shown in red that mediates protein-protein interactions, such as those with the Engrailed Homology (EH1)-containing proteins. The central portion of Gro/TLE is less well conserved and contains a Glycine/Proline-rich (GP) domain implicated in the recruitment of the Drosophila Rpd3/mammalian Histone Deacetylase (HDAC) shown in orange, a central portion (CCN) domain shown in green containing a Nuclear Localization Signal (NLS) shown in grey, and a Serine/ Proline-rich (SP) domain shown in violet. Phosphorylation sites are found in both the $\mathrm{CcN}$ and SP domains. Numbers indicate the positions of the boundary amino acids (aa). GRG-5 only contains the Q-rich domain and a GP-rich domain with aa differences compared to the long forms of Gro/TLE, which impede its ability to interact with HDAC. GRG-5 acts as a dominant negative. 
Increase in the nuclear $\beta$-catenin levels transiently converts TCF/ LEF into transcriptional activators (Figures 1A,B) (reviewed in MacDonald et al., 2009).

Observations from mammalian cells (Schuijers et al., 2014), flies (Franz et al., 2017), and amphibian (Nakamura et al., 2016) among others, reported the requirement of TCF/LEF for the transcriptional regulation of most $\beta$-catenin target genes, supporting the classical model of Wnt transcriptional regulation. Mammalian cells lacking all four genes encoding TCF/LEF proteins display perturbations in the association of $\beta$-catenin with DNA. In such cells, $\beta$-catenin was found to regulate different transcriptional targets (Doumpas et al., 2019), revealing that only when TCF/LEF is absent, $\beta$-catenin autonomously regulates a subgroup of genes whose transcription does not initially require TCF/LEF. Genome-wide analysis methods identified Wnt/TCF target genes that are available at http://www.stanford.edu/group/nusselab/cgi-bin/wnt/.

\section{TCF/LEF Members and Structure}

TCF/LEF sequence alignment and phylogenetic trees in species such as the hemichordate Saccoglossus kowalevskii (S. kowalevskii), Caenorhabditis elegans (C. elegans), Drosophila melanogaster, Hydra magnipapillata, and Ciona intestinalis reveal the presence, in the TCF/LEF structure, of the four major binding domains found in vertebrate (Atcha et al., 2007; Žídek et al., 2018), indicating that the TCF/LEF in invertebrate is probably the ancestral precursor of that described in vertebrate. Further complexity has been added through evolution following the emergence of the different TCF/LEF isoforms in mammals which are generated through alternative transcription, translation start sites, and alternative splicing (reviewed in Hoppler and Waterman, 2014).

Structural and functional analysis of TCF/LEF provided important cues on the domains mediating their transcriptional activities (Figure 2A). On their N-terminal region, all TCF/LEF isoforms have a $\beta$-catenin-binding domain (BCBD), which contains 50 amino acids (aa). Three sets of aa are involved in the TCF/LEF- $\beta$-catenin interactions: residues 2-15 (known as the $\beta$-hairpin module) fit into the groove of the central Armadillo (Arm) repeat domain (the homologue of the vertebrate $\beta$-catenin and signal transducer of wingless (Wg) signaling in flies). Residues 16-29 form an extended strand, and residues 40-51 form an $\alpha$-helix (Graham et al., 2000). TCF/LEF interaction with $\beta$-catenin is necessary for their activity (Kratochwil, 2002). Isoforms of TCF7 and LEF1 expressed from alternative promoters, and encoding proteins lacking $\mathrm{BCBD}$, behave as dominant-negative (van de Wetering et al., 1997; Hovanes et al., 2001). Recognition of the specific DNA sequence motif (CCTTTGAT(G/C)) by TCF/LEF is mediated by a highly conserved High Mobility Group (HMG)-box, whose DNAbinding domain structure and general mechanisms of DNA binding and bending, have been extensively studied (van Beest et al., 2000; reviewed in; Malarkey and Churchill, 2012). This HMG-box is followed by a Nuclear Localization Signal (NLS). The BCBD and the DNA-binding domain are separated by a less conserved context-dependent regulatory domain (CRD), partly encoded by an exon (exon VI), which can be alternatively spliced in all TCF/LEF except TCF7L1. Two conserved aa motifs, LVPQ and SxxSS, flank exon VI in Xenopus Tcf7l1 and Tcf7l2, but not in Tcf7 or Lef1, and can be alternatively spliced in Tcf712. Mutations in these two motifs validate their strict requirement for Tcf7l1 repressive activity. Furthermore, their insertion into the lef 1 sequence abolishes Lef1 activator capacity, as detected through its inability to induce an ectopic secondary axis when injected ventrally in Xenopus embryos (Pukrop et al., 2001; Gradl et al., 2002; Liu et al., 2005). Other studies suggest that the Gro/TLEbinding domain encompasses the entire CRD and part of exon VII. Indeed, alternative splicing within the CRD (exon V to exon VII) modifies the interactions of TCF/LEF with Gro/TLE (Young et al., 2019) (reviewed in Hoppler and Waterman, 2014). The C-terminal tail is the most variable region among the TCF/LEF, where much of the aa sequence exhibit a low level of conservation. The C-terminal tail exists either as a long C-terminal extension, referred to as $\mathrm{E}$ tail, that contains additional domains, or as a short C-terminal extension, referred to as B tail, lacking the additional transcriptional regulators' binding domains. Whereas TCF7L1 only carries an E tail, the LEF1 gene lacks the E-tail-encoding exon (Atcha et al., 2003). The E-tails encode two copies of a specific short motif (PLDLS) that binds the evolutionarily conserved co-repressor phosphoprotein C-terminal-Binding Protein (CtBP). Indeed, CtBP binds to both Tcf7l1, and the Tcf7l2 isoforms carrying an $\mathrm{E}$ tail (Brannon et al., 1999; Valenta et al., 2003; Fang et al., 2006). An additional small, highly conserved 30 aa motif (CRARF) is present in invertebrate TCF/LEF and in vertebrate splice variants Tcf7-E and Tcf712-E, but not in Tcf7l1. CRARF is required for the $\beta$-catenin-mediated transcriptional activation of the lef 1 promoter, and forms a C-Clamp (Cysteine-rich domain) that allows TCF/LEF to bind an additional DNA motif known as the Helper site (5'-RCCGCCR-3') (Atcha et al., 2007; Ravindranath and Cadigan, 2014).

\section{A Brief Picture of the Evolution of the TCF/ LEF Family}

TCF/LEF are metazoan inventions (Adamska et al., 2010). In choanoflagellates, which are unicellular eukaryotes considered the closest known relatives to metazoans, there is no evidence supporting the existence of any TCF/LEF protein and the only found component of the Wnt pathway is GSK3 (King et al., 2008). In invertebrate genome, only one Tcf/Lef gene is detected (reviewed in Hoppler and Waterman, 2014). One exception is found in the phylum of Platyhelminthes, in which five Tcf/Lef have been found in the genome of the flatworm Schmidtea mediterranea. Only two of these Tcf/Lef have a putative $\mathrm{BCBD}$, which suggests a function in mediating Wnt transcription (Brown et al., 2018).

Most of our knowledge about TCF/LEF activity in invertebrate derives from studies performed in Drosophila and C. elegans. As in vertebrate, their Tcf/Lef is converted from a transcriptional repressor to activator by increasing nuclear levels of $\beta$-catenin. Drosophila Arm/ $\beta$-catenin promotes transcriptional activation by binding Pangolin (Pan), the Tcf/Lef in fly (referred to as Tcf) (van de Wetering et al., 1997). Consequently, co-repressors such as 
Gro are displaced, allowing Arm binding to transcriptional coactivators such as Pygopus (Pygo) (Parker et al., 2002). As in vertebrate, in the absence of Arm, Tcf acts as a transcriptional repressor (Cavallo et al., 1998). Transcriptional repression appears to be directly mediated by the Tcf/Arm interactions with a specific DNA sequence motif (AGAWAW). The exchange of the AGAWAW motif into a standard Tcf-binding site (CCTTTGAT $(\mathrm{G} / \mathrm{C})$ ) reversed the mode of regulation, resulting in Wnt-mediated activation instead of repression. Whereas both transcriptional activation and repression require binding of Arm to the N-terminal part of Tcf, allosteric regulation has been proposed to explain differences in Tcf/Lef transcriptional capacity. Indeed, Tcf binding to different DNA motifs may allow its interaction with distinct co-regulators, which subsequently controls its transcriptional activity (Blauwkamp et al., 2008).

In C. elegans, loss-of-function phenotypes indicate a dual regulatory mode for the Tcf/Lef termed POsterior Pharynx defect (POP1). An interesting mechanism has been reported for mesoderm and endoderm fate specification during embryogenesis (Rocheleau et al., 1997; Thorpe et al., 1997). At the four-cells stage, two sister cells, the anterior (MS) and the posterior (E) are fated to respectively generate the mesoderm and the endoderm. Higher levels of pop1 are detected in the MS blastomere (Lin et al., 1995), where it represses the transcription of Wnt-responsive endodermdetermining gene end 1 through the recruitment of the histone deacetylase HDA-1 and UNCoordinated (UNC)-37 (the homologue of the Gro/TLE) (Calvo et al., 2001). In a POP1 mutant, both blastomeres adopt an endoderm-like fate. However, in the E blastomere receiving Wnt signals, WRM1/ $\beta$-catenin binds to the $\mathrm{N}$-terminal domain of POP1 protein and decreases its nuclear levels, alleviating POP1 repressive activity, which will then activate the expression of end1 and induce the specification of the endodermal fate (Rocheleau et al., 1997; Shetty et al., 2005). Another model proposes that the switch of POP1 from a transcriptional repressor to an activator depends on its DNAbinding site. The C-terminal tail of POP1 contains a C-clamp, which enables POP1 to recognize another DNA motif (the Helper site). When Wnt signaling is activated, $\beta$-catenin stabilizes the interaction between the C-Clamp of POP1 and the Helper sites found in the end 1 sequence, which enables end1 transcription (Bhambhani et al., 2014).

\section{The vertebrate TCF/LEF are somewhat specialized in transcriptional activation or repression}

In vertebrate, the founder members of the TCF/LEF family are TCF7 (van de Wetering et al., 1991) and LEF1 (Travis et al., 1991), initially identified as lymphocyte-regulators in mice. The two other members, TCF7l1 and TCF712 have been characterized few years later (Castrop et al., 1992).

TCF/LEF are largely expressed during vertebrate embryogenesis in some overlapping but also distinct regions including the central nervous system, suggesting a functional redundancy of the TCF/LEF members. For instance, in mice, $T c f 7 l 2$ and Lef 1 transcripts are detected in the mesencephalon and the diencephalon (Korinek et al., 1998). In zebrafish, tcf1 and lef1 expression overlaps in the tail bud, fin buds and paraxial mesoderm (Veien et al., 2005). Observations made in lung epithelial progenitors also supports redundant and additive functions between the different TCF/LEF members (GernerMauro et al., 2020). However, genetic mutants lacking a single $T c f / L e f$ gene, as well as double knockout (KO) mutants, exhibit severe developmental alterations (van Genderen et al., 1994; Galceran et al., 2000), indicating expanded and diversified roles for each TCF/LEF. Based on these findings among others, a specific activity as Wnt transcriptional activator and/ or repressor has been attributed to each TCF/LEF.

Lef1 and Tcf7l2 KO mice show reduced Wnt transcriptional activity and are considered to mostly act as activators of the pathway (Korinek et al., 1998; Kratochwil, 2002). Similarly, analysis in zebrafish reveals activating functions for Tcf7, Lef1, and Tcf712. Loss of Lef1, expressed in several embryonic tissues, specifically the neural crest, decreases $\beta$-catenin activity (Dorsky et al., 1999, 2003). Additional observations from Tcf7l2 mutants show that it maintains proliferation of the intestinal epithelium through activating Wnt target genes' transcription (Muncan et al., 2007).

In contrast, numerous studies strongly argue that Tcf7l1 mediates Wnt repressive activity. Mice depleted of $T c f 7 l 1$ gene phenocopy those with ectopic activation of Wnt signaling, suffering severe forebrain abnormalities in addition to perturbations in the midbrain and hindbrain (Merrill et al., 2004). Similarly, the zebrafish genome contains two tcf7l1 genes, headless hdl/tcf7lla (Kim et al., 2000) and tcf7llb (Dorsky et al., 2003), giving a total of five tcfllef genes. The two Tcf7l1 appear to normally act as transcriptional repressors. hdl/tcf7lla mutants exhibit truncated Tcf7l1 protein, which cannot undergo nuclear translocation. Such mutants show severe head defects including a lack of eyes, forebrain, and a part of the midbrain, a hallmark of Wnt overactivation. This phenotype could be rescued by overexpressing $t c f 7 l 1 b$, which in this context also act as a negative regulator of the Wnt pathway (Dorsky et al., 2003). Compared to zebrafish, the medaka genome contains a single $t c f 7 l 1$ gene. Medaka lacking $t c f 7 l 1$ have the same phenotype as the double-mutant zebrafish hdl/tcf7llb (Doenz et al., 2018).

Some of the most informative studies regarding transcriptional activities of the four TCF/LEF members came from investigating the development of Spemann organizer (SO) in the amphibian Xenopus (also see next section). The early Xenopus embryo expresses three maternally inherited tcf/lef mRNAs: $t c f 7, t c f 7 l 1$ and $t c f 7 l 2$ (Molenaar et al., 1998; Houston et al., 2002; Roël et al., 2002). Tcf/Lef activities are not redundant during mesoderm induction in amphibian. At late blastula/early gastrula stages, maternally encoded $t c f 7 l 1$ represses the dorsal organizer genes' expression (Houston et al., 2002), whereas both $t c f 7$ and $t c f 7 l 2$ act as transcriptional activators of SO genes (Standley et al., 2006). In this developmental context, whereas an activating form of tcf7l1 can rescue the Tcf7-morphant phenotype, only a constitutive repressor form of $t c f 7 l 1$ rescues the Tcf7l1-morphant phenotype (Liu et al., 2005). Taken together, these observations indicate that during early Xenopus mesoderm induction, Tcf7l1 is mostly required for transcriptional repression, whereas Tcf7 and Tcf7l2 mostly 
mediate transcriptional activation. Interestingly, lef1 transcripts are first detected after the mid-blastula transition (MBT) (Molenaar et al., 1998), and during mesoderm induction, Lef1 transcriptional activity appears to be redundant with that of Tcf7 (Liu et al., 2005).

\section{The Interaction Between TCF/LEF and Gro/ TLE: A Partnership at the Core of TCF Inhibitory Activity}

All the TCF/LEF members need to bind with nuclear co-factors to regulate target genes' transcription. A key insight into the mechanism of Wnt transcriptional inhibition mediated by the TCF was the finding that they can directly bind to members of the Gro/TLE family of transcriptional co-repressors.

\section{Structure and Interactions of Gro/TLE Co-repressors}

Gro/TLE are evolutionary conserved nuclear proteins. The invertebrate genome encodes a single member: Gro, initially identified in Drosophila, and UNC-37 in C. elegans, both of which antagonize signaling by Wnt (Cavallo et al., 1998; Calvo et al., 2001). Four members have been identified in human, known as TLE1-4, and in mice, named the Groucho-Related Genes (GRG1-4) (reviewed in Jennings and Ish-Horowicz, 2008; Turki-Judeh and Courey, 2012). In mice, a fifth family member (GRG-5) has also been identified as a gene encoding a shorter variant. GRG-5 is thought to act as a naturally occurring dominant negative (Table 1) (Brantjes, 2001; Wang et al., 2004).

A conserved structural organization comprising five domains characterizes Gro/TLE proteins (Figure 2B). Lacking a DNAbinding domain, Gro/TLE rely on their interaction with transcription factors for their specific recognition of promoter and/or enhancer DNA sequences. The highly conserved N-terminal glutamine-rich (Q) domain contains two motifs termed the amphipathic a-helices (AH1 and AH2), which mediate both Gro/TLE homo-oligomerization and their interactions with various transcription factors, including TCF/LEF (reviewed in Jennings and Ish-Horowicz, 2008). The central portion of Gro/TLE contains three less well-conserved domains. Gro/TLE was found to bind to the Drosophila Hdac known as Rpd3 (Chen et al., 1999), and with the mammalian HDAC1 an interaction mediated by the glycine $(\mathrm{G})$ and proline (P)-rich domain (GP) (Chen et al., 1999; Arce et al., 2009). Second, the central (CcN) domain which includes a NLS, and third, a Serine (S) Proline (P)rich domain (SP) generally involved in repression. The $\mathrm{CcN}$ and SP domains contain phosphorylation sites, which can modulate Gro/ TLE-mediated repression (reviewed in Jennings and Ish-Horowicz, 2008). Of note, GRG5 contains the TCF/LEF binding domain and a GP domain that carries mutations impeding its ability to interact with HDAC (Brantjes, 2001). At their C-terminal end, Gro/TLE have a four tryptophan-aspartic acid repeat domain (WD), which is highly conserved across evolution. The WD motif is involved in nucleosome binding and condensation (Sekiya and Zaret, 2007), and mediates Gro/TLE interactions with repressor proteins. The WD motif of Gro/TLE interacts with two distinct peptidic motifs, the
Engrailed Homology-1 (EH1) motif, and the WRPW (Trp-Arg-ProTrp) motif.

The EH1 motif is a Phenylalanine/Isoleucine/Leucine (FIL)-rich domain (FxIxxIL), required for transcriptional repression in vitro and in vivo (Smith and Jaynes, 1996; Muhr et al., 2001; Jennings et al., 2006). The EH1 motif is found in a large number of HD-containing TFs involved in neuronal specification such as Gastrulation Brain homeobox 2 (GBX2), Orthodenticle homeobox 2 (OTX2) (Heimbucher et al., 2007), Forkhead box (FOX) family of TFs (Yaklichkin et al., 2007), Engrailed (EN) (Jimenez et al., 1997) and BARHL that are notably the only Gro/TLE partners containing two EH1 domains (Offner et al., 2005). The TF Dorsal is involved in DV axis patterning in Drosophila. Dorsal was found to physically interact with Gro. Interestingly, in embryos lacking Gro, Dorsal functions as a transcriptional activator rather than as a repressor (Dubnicoff et al., 1997). It has been demonstrated that Gro interacts with a motif with partial homology to the EH1, located in the C-terminal part of Dorsal (Flores-Saaib et al., 2001). This interaction is weak and is stabilized by the presence of additional Gro-binding repressors (Valentine et al., 1998).

The second Gro/TLE-interacting motif is the WRPW present in basic-helix-loop-helix (bHLH) proteins including the Hairy/ Enhancer of Split $(\mathrm{E}(\mathrm{spl})) / \mathrm{HES}$ proteins, transcriptional repressors that function as downstream targets of activated Notch receptors (Grbavec et al., 1998) (reviewed in Cinnamon and Paroush, 2008; Turki-Judeh and Courey, 2012). In the absence of Notch signaling, Gro/TLE is recruited via Hairless to a complex containing Suppressor of Hairless $(\mathrm{Su}(\mathrm{H}))$ and $\mathrm{CtBP}$, which represses Notch target genes, including $\mathrm{E}(\mathrm{spl})$. Upon activation of Notch signaling, the Notch intracellular domain (NICD) enters the nucleus, displaces the Gro-containing complex, recruits Mastermind (Mam) on $\mathrm{Su}(\mathrm{H})$ an interaction which further results in the transcriptional activation of $\mathrm{E}(\mathrm{spl}) . \mathrm{E}(\mathrm{spl})$ encoded factors interact with Gro/TLE to repress proneural genes (reviewed in Cinnamon and Paroush, 2008; TurkiJudeh and Courey, 2012). In Drosophila, and mammals association of Gro/TLE to bHLH proteins is required in cell fate decisions during tissue development including neurogenesis, segmentation, sex determination and myogenesis (Paroush, 1994; Jimenez et al., 1997). The WRPW motif has been demonstrated to be a functional transcriptional repression domain. It is sufficient to confer active repression to Hairy-related proteins or a heterologous DNA-binding protein through its ability to recruit Gro/TLE to target gene promoters (Fisher et al., 1996). Similar to Dorsal, in Drosophila, the Runx family member Lozenge that contains a WRPW motif exhibit low affinity for Gro/TLE and requires the Cut $\mathrm{HD}$ protein to form a stable repressive complex (Canon, 2003).

\section{Gro/TLE Acts as Co-repressor in the Presence and Absence of $\beta$-catenin}

The Gro/TLE-binding site in the central portion of TCF/LEF extends and overlaps the $\beta$-catenin binding site (Daniels and Weis, 2005). Therefore, association of Gro/TLE with TCF/LEF counteracts the TCF/ $\beta$-catenin transactivation activity (Cavallo et al., 1998; Roose et al., 1998; Brantjes, 2001). Together with other observations, these data lead to the generally accepted 
model where $\beta$-catenin activates Wnt-responsive genes by simply displacing Gro/TLE. Whereas recent studies provide arguments for a more complex regulation of Wnt-driven transcriptional switch (reviewed in Ramakrishnan et al., 2018), a large spectrum of genes are regulated by both $\beta$-catenin and Gro/TLE through their respective interactions with TCF/LEF. Chromatin immunoprecipitation sequencing (ChIP-seq) data from Xenopus embryos provide over $80 \%$ correlation between $\beta$-catenin and Gro/TLE-binding sites (Nakamura et al., 2016). In mouse hair follicle stem cells, more than half the genes occupied by TCF/LEF are also occupied by Gro/TLE (Lien et al., 2014).

The way Gro/TLE mediate transcriptional repression is still a matter of debate. Recent observations indicate that Gro/TLE could act either short distance via modulating RNApolymerase II (RNA-Pol II) activity, and/or long distance via chromatin remodeling. ChIP-seq analysis combined to RNA-seq data performed in Drosophila identified the Gro/TLE direct targets. Such analysis suggested that Gro/TLE doesn't affect the recruitment of RNA-Pol II to the transcription start sites but further increases RNA-Pol II pausing time (Kaul et al., 2014). Other studies indicate that in some context, Tcf/Gro complex promotes compaction of the chromatin when the canonical Wnt pathway is switched off. As previously mentioned, Gro/TLE interact with Hdac. In the presence of an Hdac-inhibitor, Wnt target genes are de-repressed (Billin et al., 2000). It is therefore possible that Gro/TLE interaction with Hdac drives long distance, transmittable changes in the chromatin state. Other studies argue that Hdac recruitment does not account for full co-repressor activity, suggesting that another Gro/TLE-dependent silencing could occur via tetramerization of Gro on a Tcf711/Gro complex, thereby promoting structural transitions of chromatin leading to transcriptional repression (Sekiya and Zaret, 2007; Chodaparambil et al., 2014).

\section{The Gro/TLE and TCF/LEF interaction(s) in Early Axis Specification}

In Xenopus embryos, injection of gro represses transcription of Wnt target genes (Roose et al., 1998), and mutations in Gro/TLEbinding sites of $t c f 7 l 1$ reduces Tcf7l1 repressive activity (Liu et al., 2005; Tsuji and Hashimoto, 2005). Analysis performed on the Xenopus siamois (sia) promoter demonstrated that Tcf/Lefbinding sites mediate both basal repression and $\beta$-catenindependent activation at the W-CRM (Brannon et al., 1997; Fan et al., 1998). More recently, large-scale analysis demonstrates that in the dorsal blastomeres, Gro/TLE binds to the same W-CRM as $\beta$-catenin (Yasuoka et al., 2014; Nakamura and Hoppler, 2017; Afouda et al., 2020). In this context a few lines of evidence indicate that $\beta$-catenin activates Wnt-responsive genes by displacing the whole Tcf711/Gro repressor complex and replacing it with an activator complex, containing $\beta$-catenin in association with Tcf7 (Chambers et al., 2017) (reviewed in Cinnamon et al., 2008; Sokol, 2011; Ramakrishnan et al., 2018)

In conclusion, the mechanisms by which Gro/TLE mediate transcriptional repression in the presence and/or absence of TCF/
LEF are still not fully understood. To add complexity, both TCF/ LEF and Gro/TLE proteins are targets for developmental signals, which influence the affinity of Gro/TLE to TCF/LEF and/or W-CRM. Thereby, the developmental and cellular contexts in which Gro/TLE repression causes epigenetic regulations via the binding of HDAC by Gro/TLE as well as the exact role(s) of such transcriptomic regulations during development are still poorly understood.

\section{TCF/LEF AND BARHL2 IN THE DEVELOPMENTAL DYNAMICS OF SPEMANN ORGANIZER (SO)}

\section{Both Tcf/Lef Repressor and Activator Functions Are Required for Normal SO Development}

One of the earliest, well-documented, and evolutionarily conserved functions of $\mathrm{Wnt} / \beta$-catenin signaling is the induction of the blastopore lip organizer. The discovery made by Spemann and Mangold in 1924 has revolutionized our understanding of embryonic axis formation. In their classic transplantation experiment in newt, the authors showed that a mesodermal region - the dorsal lip of the blastopore - of a gastrula embryo induces a secondary axis including a complete nervous system when grafted ventrally (reviewed in De Robertis et al., 2000). This primary embryonic organizing center known as SO determines the dorso-ventral (DV) body axis. Requirement of canonical Wnt signaling for axis formation has been demonstrated following overexpression of Wnt signaling components. For instance, in Xenopus, wnt1 (McMahon and Moon, 1989), wnt8 (Sokol et al., 1991), and $\beta$-catenin (McCrea et al., 1993) can induce a complete dorsal axis when overexpressed ventrally. A similar phenotype has been observed when two Wnt inhibitors are depleted: Tcf7l1 (Merrill et al., 2004) and Axin2 (Zeng et al., 1997). More recently, it was shown in non-bilaterian metazoan species that the same molecular mechanism was used for inducing secondary axes as in chordates: the $\mathrm{Wnt} / \beta$-catenin signaling, indeed demonstrating that the emergence of the $\mathrm{Wnt} / \beta$-catenin driven blastopore-associated axial organizer predates the cnidarianbilaterian split, which occurred over 600 million years ago (Kraus et al., 2016).

Investigations from the past decades lead to the current model of SO development. Before initiation of zygotic transcription, Tcf7l1 represses gene transcription throughout the embryo (Figure 3) (Molenaar et al., 1996; Houston et al., 2002). Accumulation and stabilization of $\beta$-catenin by maternal determinants in the nucleus of the dorsal cells, inhibit Tcf7l1 repressors' activity (Schneider et al., 1996; Larabell et al., 1997), and activate the transcription of sia and siamois homologue 2 (twin) (Lemaire et al., 1995; Carnac et al., 1996), which in turn activate the transcription of 123 genes, including goosecoid (gsc) and chordin (chd), leading to the formation of the SO territory. All genes de-repressed by $\beta$-catenin in this region have been identified (Ding et al., 2017b). sia and twin are directly regulated by binding $\mathrm{Tcf} / \mathrm{Lef}$ to their promoters, and poised 

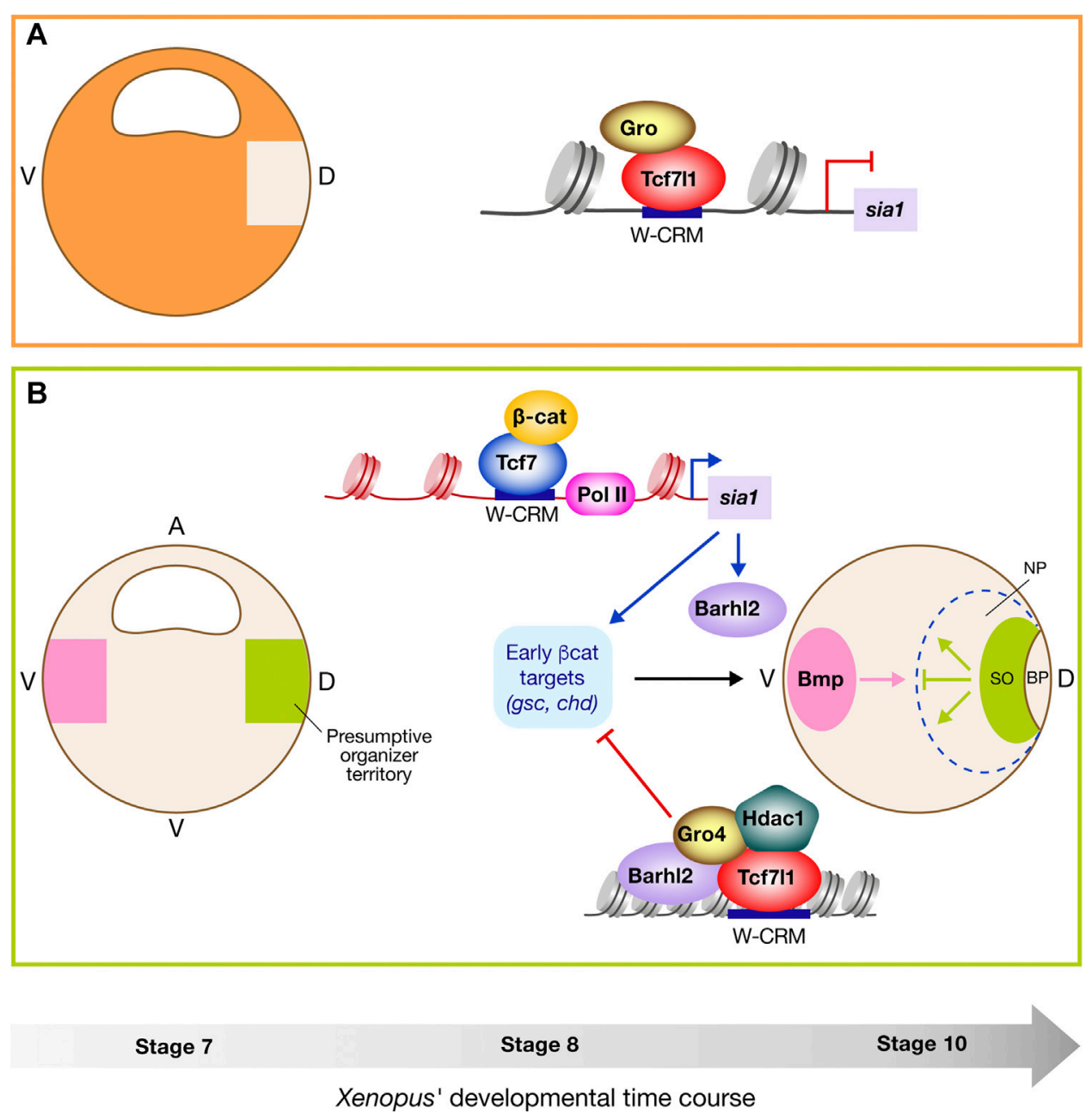

FIGURE 3 | Barhl2 switches off early $\beta$-catenin response during establishment of Spemann organizer in Xenopus. (A) Maternally encoded Tcf7l1 represses Wnt target genes' transcription (e.g., siamois-1 (sia1)) throughout the entire embryo except dorsally in the presumptive organizer territory starting at stage 7. (B) Dorsally (green area), nuclear $\beta$-catenin ( $\beta$-cat) level locally increases allowing its interaction with T-Cell Factor (probably mostly Tcf7 and Tcf7l2), and the initiation of sia1 transcription. Between stage 8 and 9, Sia1, together with $\beta$-cat, induce expression of the dorsal early $\beta$-cat target signature including goosecoid (gsc) and chordin (chd) leading to the formation of Spemann organizer (SO). Evidence argues that around the same time, sia1 induces barh/2 transcription. Barhl2 being a part of a repressive complex together with Groucho-4 (Gro4), Tcf7l1, and Histone deacetylase-1 (Hdac1), switches off the early $\beta$-cat dorsal signature via an inherited epigenetic regulatory mode thereby limiting SO establishment in time and/or space. SO gives rise to the prechordal plate and the notochord, two tissues that send planar and vertical signals to the overlying prospective neuroepithelium. At stage 10, signals secreted by the SO, including Bone Morphogenetic Protein (Bmp) inhibitors and Wnt signals, enable initiation of the dorsal developmental program: The first blastopore lip cells invaginating into the embryo will give rise to the prechordal plate, followed by the cells that will generate the notochord. Together, the prechordal plate, and the notochord, will send planar and vertical signals that both induce and pattern the overlying neuroepithelium and thereby constitute a secondary organizer (the axial organizer). The prechordal plate plays a major role in inducing and patterning of the anterior neural plate, generating the forebrain and midbrain. The notochord participates in formation of the Sonic hedgehog (Shh)-secreting floor plate and induces and patterns the posterior neural plate (reviewed in Stern, 2002; Wessely and De Robertis, 2002; Niehrs, 2004; Wilson and Houart, 2004; Hoch et al., 2009; Ozair et al., 2013; Brafman and Willert, 2017). V, ventral; D, dorsal; BP, blastopore; NP, neuroepithelium; A, Animal pole; V, Vegetal pole.

for transcriptional activation by $\beta$-catenin before the Mid blastula transition (MBT) (Brannon et al., 1997; Laurent et al., 1997; Fan et al., 1998; Blythe et al., 2010). In the absence of $\beta$-catenin, Tcf7l1, together with Gro/Tle, inhibit sia and twin transcription (Roose et al., 1998). More recently, a thorough transcriptomic analysis, combined with genome-wide $\beta$-catenin association using ChIP-seq, identified stage-specific direct Wnt target genes. The direct comparison of genome-wide occupancy of $\beta$-catenin with a stage-matched Wnt-regulated transcriptome reveals that only a subset of $\beta$-catenin-bound genomic loci are transcriptionally regulated by Wnt signaling. The differences in classes of direct Wnt target genes appear to be context specific, and dependent on the presence of co-factors such as FoxH1, Nodal/TGF $\beta$ signaling (Afouda et al., 2020), Bone Morphogenetic Protein (BMP), and FGF signaling (Nakamura et al., 2016). These studies reveal that the cellular transcriptional responses to Wnt signal are highly dependent on the context, and thereby on the tissue, the developmental steps, the presence of co-factors and/or activation of co-signaling pathways (reviewed in Nakamura and Hoppler, 2017). 


\section{The Evolutionary Conserved BARHL Proteins Interact Independently With Both Gro/TLE and TCF/LEF}

The Bar-class HD, BarH1 and BarH2, are HD-containing transcription factors initially discovered in Drosophila (Kojima et al., 1991; Higashijima et al., 1992). Barhl genes have subsequently been identified in fish (zebrafish, medaka), amphibian (Xenopus), birds (chicken), mammals (mouse, human), nematode (C. elegans) and S. kowalevskii among others (Lowe et al., 2003; Pani et al., 2012; Yao et al., 2016). Phylogenetic analysis shows that BARHL1 and BARHL2 proteins are extremely well conserved in the chordate phylum and are predominantly expressed in the central nervous system (CNS), where their expression patterns are distinct but partially overlapping (Figure 4) (Bulfone, 2000; Patterson et al., 2000; Offner et al., 2005; Colombo et al., 2006) (reviewed in Schuhmacher et al., 2011). BARHL1 and BARHL2 are involved in diverse processes such as the acquisition of a neural identity in the retina, specification of commissural neurons in the spinal cord and cell migration in the cerebellum and the hindbrain (Chellappa et al., 2008; Ding et al., 2009; Jusuf et al., 2012) (reviewed in Reig et al., 2007).

BARHL proteins are characterized by a conserved HD sequence of about 60 amino acids, which forms a threedimensional helix-loop-helix structure required for their fixation to DNA (Figures 4A,B) (Gehring et al., 1994). Unlike other homeoproteins, BARHLs contain a tyrosine $(\mathrm{Y})$ at site 49 as opposed to phenylalanine (F) at this site of the HD. Whilst the biological significance behind this substitution is unknown; it is thought that there could be a difference in the specificity of the DNA recognition motif. BARHL sequence also contains an NLS, and at their amino-terminal region, two EH1 domains. Sequence comparison reveals a conserved domain with an unknown function at the C-terminal part of BARHL proteins.

Biochemical experiments performed in both mammalian cells and Xenopus embryo validate the physical interaction between BARHL2 and Gro/TLE. Surprisingly, BARHL2 was found to interact with TCF/LEF, more specifically TCF7l1, and dramatically enhance the ability of TCF7l1 to coimmunoprecipitate Gro4/TLE4, at least in mammalian cells. This interaction is independent of TCF7L1 binding to Gro/ TLE. Functional observations confirm that Barhl2 enhances the capacity of to repress transcription, and abolishes the $\beta$-catenin-driven activation of TCF/LEF target genes (Figure 1C) (Sena et al., 2019).

\section{Barhl2 Normally Limits SO Formation Through Enhancing the Ability of Tcf to Repress Transcription}

In Xenopus, barhl2 is not expressed maternally. Whereas $\mathrm{W}$-CRM have been identified in the barhl2 loci (Nakamura et al., 2016), barhl2 is neither part of the early dorsal $\beta$-catenin signature, nor induced by overexpression of RNA coding for wnt8b. It is however expressed following the initiation of early $\beta$-catenin induction, and its expression increases following sia1 mRNA overexpression (Owens et al., 2016; Session et al., 2016; Ding et al., 2017b; Sena et al., 2019), suggesting that at these developmental stages, barhl2 transcription is under the control of both sial and $\beta$-catenin (Figure 3).

In Xenopus, overexpression of barhl2 generates massive developmental defects including loss of the SO territory and all anterior structures, including the cement gland and the head. In contrast, Barhl2 depletion expands both the organizer territory and its signaling activity, as detected through a massive increase in neuroepithelium size, and patterning alterations (Offner et al., 2005; Sena et al., 2019). Experimental evidence demonstrates that these developmental defects are direct consequences of Barhl2 normally enhancing Tcf7l1-mediated transcriptional repression. These observations lead to a model in which stabilization of $\beta$-catenin first de-represses Tcf7l1, and then initiates the dorsal developmental program through activating Tcf7 and/or Tcf7l1. The presence of Barhl2 locks Tcf7l1 and/or Tcf7 in an inhibitory state, and consequently limits induction of the dorsal development program. In this way Barhl2 participates in progression of the blastula development, and normally limits SO formation in time and/or in space.

Analysis of Barhl2 proteins that are mutated either in their ability to interact with DNA, or to bind Gro/TLE, indicate that its normal role requires both. As previously stated, Gro/TLE can silence target genes by tetramerizing on a Tcf7l1-Gro complex (Chen et al., 1999; Chodaparambil et al., 2014). It is therefore possible that Barhl2 enhances the binding of the complex to histones, associated with the long-term silencing of Tcf/Lef target genes through increasing Gro/TLE stoichiometry in a protein complex containing Tcf7l1. Moreover, the presence of Hdac1 is detected in a protein complex containing Barhl2, Tcf7ll and Gro4. Hdac1 depletion promotes SO development. In parallel, Barhl2 depletion promotes key organizer genes' acetylation. Thereby, Hdacl activity could contribute to the Barhl2mediated repression of Wnt target genes. ChIP-qPCR observations on the promoter of $g s c$ indicate that both Barhl2 and Tcf7ll can interact with the same Tcf-W-CRM in the absence of an adjacent Barhl2-W-CRM.

Overall, these observations are consistent with Barhl2 acting over long distance via its specific binding on DNA, perhaps on super-enhancers as previously suggested (Lin et al., 2016), and inducing long-term silencing of SO target genes maybe via Hdac1 activity and/or direct interaction with chromatin. In this way Barhl2 irreversibly locks cells in a SO identity.

\section{IN THE DIENCEPHALIC PRIMORDIUM, BARHL2 LIMITS WNT/TCF ACTIVITY}

\section{Patterning and Growth of the Diencephalic Territory Requires High Levels of Wnt Signals and the Presence of the Morphogen Sonic HedgeHog (Shh)}

The forebrain (telencephalon and diencephalon) is derived from the most anterior part of the neuroepithelium: the 

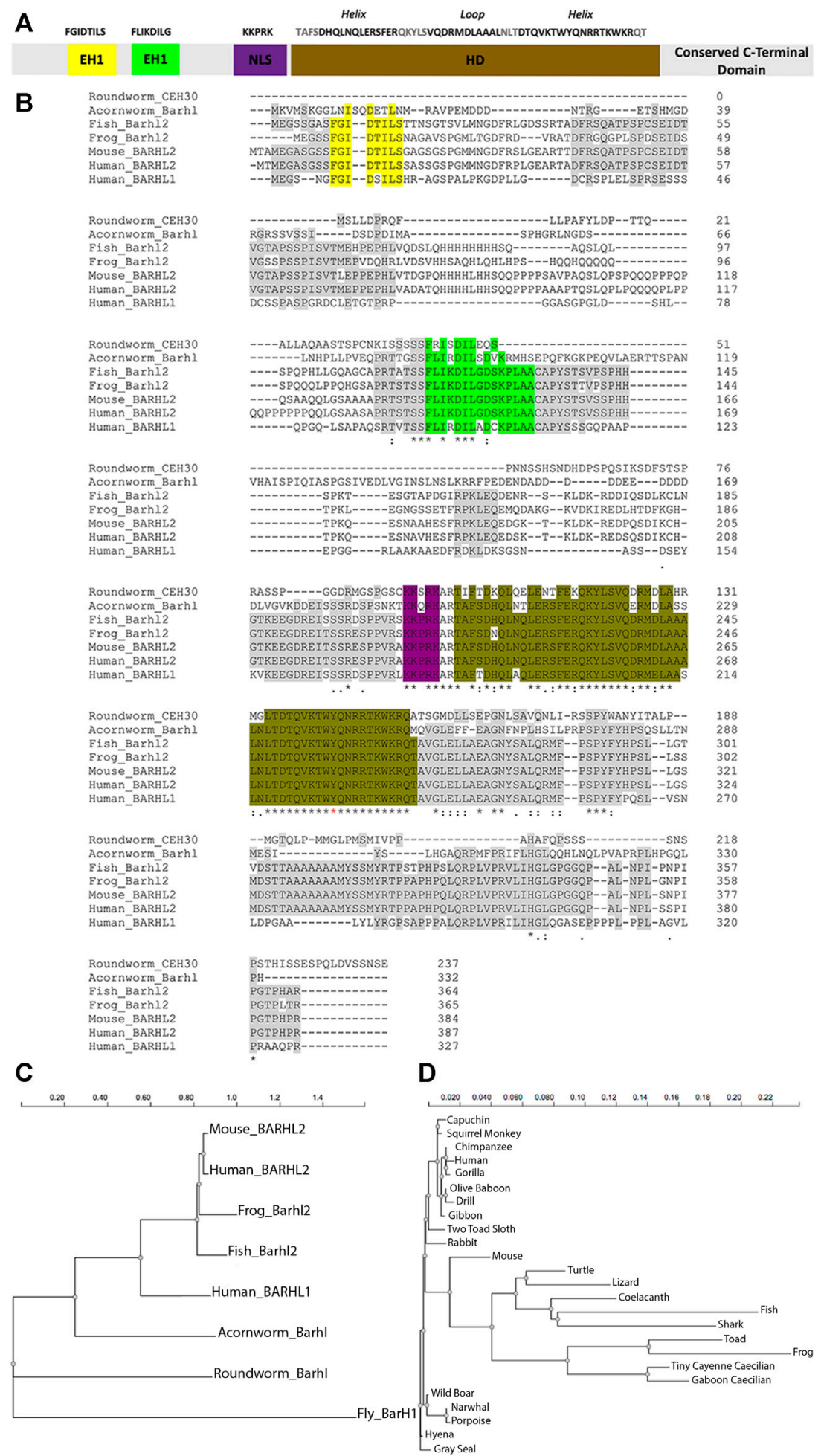

FIGURE 4 |BARHL proteins are highly conserved through evolution. (A) Scheme of BARHL1 and BARHL2 proteins. Both proteins share high similarities in their aa sequences. The most conserved regions are the two Engrailed Homology (EH1) domains shown in yellow and green, the homeodomain (HD) shown in brown, the Nuclear Localisation Signal (NLS) shown in violet, and a functionally uncharacterized C-terminal region. (B) Multiple sequence alignment of BARHL proteins. Shown is a representative selection of some BARHL2 protein sequences in vertebrate including frog Xenopus laevis (NP_001082021.1), fish Danio rerio (NP_991303.1), mouse Mus musculus (NP_001005477.1) and human Homo sapiens (NP_064447.1) among several other vertebrate sharing the same amino acid (aa) sequences, together with the human BARHL1 protein sequence (NP_064448.1), in addition to the invertebrate roundworm Caenorhabditis elegans Bar homeodomain CEH-30 (NP_508524.2) and hemichordate acornworm Saccoglossus Kowalevskii Barhl (NP_001158386.1). Mouse MBH1 (mammalian BarH1) is referred to as BARHL2.

(Continued) 
FIGURE 4 | Alignments are generated by ClustalW. Identical aa within the conserved regions are highlighted. EH1 domains (yellow and green) are highly conserved in vertebrate. However, only the second $\mathrm{EH} 1$ domain (green) is found in roundworm and acornworm. The most conserved region between vertebrate and invertebrate is the HD (brown), preceded by a NLS (purple). Other conserved aa, specifically those located on the C terminus, haven't been functionally characterized and are depicted in grey. The HD of BARHL proteins contains a tyrosine (Y) at site 49 (red asterisk), as opposed to phenylalanine (F49) in other homeoproteins. Below the protein sequences is a key denoting conserved sequence $\left({ }^{*}\right)$, conservative mutations (:), and semi-conservative mutations (.). Phylogenetic trees showing evolutionary distance between (C) the BARHL protein sequences in invertebrate and vertebrate, and (D) a larger selection of vertebrate BARHL2 protein sequences. The Trees were constructed by NGPhylogeny.fr (Lemoine et al., 2019) using FastME2.0 program which provides distance algorithms to infer phylogenies based on the balanced minimum evolution approach. The trees are drawn to scale, which represents the number of differences between sequences through evolution. Drosophila melanogaster (NP_001259642.1) shows several divergent regions: fly BarH1 (mammalian BARHL2) protein carries the first EH1 domain and HD but has several additional aa found on the $\mathrm{N}$-terminal and C-terminal parts. BARHL2 protein sequence is similar in all higher vertebrate (less than $2 \%$ difference).

prosencephalic neural plate. Fate mapping analysis revealed that the telencephalon emerges from the most anterior part of the neural plate, whereas the diencephalon is formed within the caudal forebrain. Whereas inhibition of Wnt pathway is strictly necessary for telencephalic development (Glinka et al., 1998) (reviewed in Wilson and Houart, 2004), growth and patterning of the diencephalic territories (thalamus and epithalamus) require high levels of Wnt. While the Wnt1 or Wnt $3 A \mathrm{KO}$ mice lose both the midbrain and hippocampal areas, double Wnt $3 A / W n t 1$ mutant embryos exhibit an additional reduction in the diencephalon, caudal hindbrain, and rostral spinal cord (Thomas and Capecchi, 1990; Lee et al., 2000). Conversely, ectopic expression of Wnt1 or Wnt3A induces the enlargement of the neural tube along the DV axis, without altering the cellular identities of diencephalic neurons (Megason and McMahon, 2002; Panhuysen et al., 2004). Zebrafish masterblind ( $m b l$ )-mutant embryos carrying a mutation in the GSK3-binding domain of Axin1, which constitutively activates Wnt signaling, show a net reduction in the telencephalic and retinal territories in favor of the diencephalic territory (Heisenberg, 2001). Indeed, the diencephalic primordium, more specifically the diencephalic alar and roof plates, express Wnt ligands such as Wnt3, Wnt3A, Wnt8B, Wnt4 and Wnt2B (Colombo et al., 2006; Juraver-Geslin et al., 2011, 2014; Schuhmacher et al., 2011). Wnt target genes' expression as well as the Wnt signaling machinery are enriched in the thalamus of all vertebrate analyzed so far (Jones and Rubenstein, 2004; Shimogori et al., 2004; Quinlan et al., 2009; Mattes et al., 2012).

Besides its role in fate determination, Wnt promotes cellcycle progression, and cell growth. Its ability to modulate the activity of GSK $3 \beta$ promotes a general increase in protein stability, specifically that of $\beta$-catenin (Taelman et al., 2010), and through activation of Target of Rapamycin (TOR) pathway, it stimulates growth and protein synthesis. $\beta$-catenin nuclear accumulation induces TCF/LEF-mediated expression of the proto-oncogene $c-M y c$ (He et al., 1998), which encodes a bHLH leucine zipper (bHLHZip) TF that has two distinct roles in the G1 progression. On one hand, it increases the expression of CyclinD1 and CyclinD2 that promotes progression from the $\mathrm{G} 1$ to the $\mathrm{S}$ phase; on the other, it represses the cell cycle inhibitors p27Kip1 and p21Cip1, thereby promoting cell cycle progression, and enhancing cell proliferation (reviewed in Juraver-Geslin and Durand, 2015).
The Sonic hedgehog (Shh)-secreting Mid-Diencephalic Organizer (MDO), also known as the Zona Limitans Intrathalamica (zli), develops within the diencephalic primordium (Larsen et al., 2001). Within the thalamic complex, Shh secreted by zli cells participates in the survival, growth, and patterning of neuronal progenitor subpopulations (Hashimoto-Torii et al., 2003; Scholpp et al., 2006, 2007; Vieira and Martinez, 2006). Mice lacking Shh show severe defects in most of the diencephalic territory (Chiang et al., 1996; Ishibashi and McMahon, 2002). Investigation of the chick neural tube growth revealed an epistatic relationship between Shh and Wnt in progression of the G1 cell cycle phase: Shh permits transcriptional activation of $T c f 7 l 1$ and $T c f 7 l 2$, which then induces $\beta$-catenin dependent expression of Cyclin-D1 (Alvarez-Medina et al., 2008). Phenotypic observations of Shh mutated mice suggest a conservation of these interactions in the diencephalon. Such mice develop a reduced diencephalon with decreased Tcf7l2 expression (Ishibashi and McMahon, 2002).

\section{In the Diencephalon, Barhl2 Acts as a Brake on Progenitors' Proliferation by Limiting Wnt Activity}

Shh and Wnt synergistically promote proliferation in the alar diencephalon, whereas cell-cycle analysis in chicken and mice reported slow proliferation kinetics in the diencephalon compared to its neighboring territories (reviewed in Martínez and Puelles, 2000). Moreover, diencephalic changing patterns observed upon manipulation of Wnt activity appear to be primarily due to altered fate specification rather than changes in proliferation (reviewed in Wilson and Houart, 2004). barhl2 transcripts are detected in the diencephalic histogenic field at late gastrula/early neurula stages in Xenopus (Offner et al., 2005; Juraver-Geslin et al., 2011), zebrafish (Staudt and Houart, 2007), and mice (Mo et al., 2004). In the diencephalic anlage, Barhl2 acts upstream of Shh in establishment of the zli and its absence generates massive defects specifically in the patterning of the alar diencephalon (Juraver-Geslin et al., 2014; Yao et al., 2016; Ding et al., 2017a) (reviewed in Sena et al., 2016). Besides its role in zli formation, Barhl2 normally limits diencephalic progenitors' proliferation: Barhl2-depleted Xenopus embryos exhibit both a dramatic hyperplasia, and a neuroepithelial architectural disorganization in the caudal forebrain (Juraver-Geslin et al., 2011, 2014). In depth analysis of Barhl2-depleted embryos revealed an excessive Wnt 
transcriptional activation that stimulates neuroepithelial cell proliferation and induces defects in $\beta$-catenin intracellular localization together with an upregulation of axin2 and cyclinD1. Measurement of the relative velocity of the cell cycle in Barhl2-depleted embryos reveals a shortening of the cell cycle length $(6$ versus $8 \mathrm{~h})$. As the length of the $\mathrm{S}$-phase in these cells remains unchanged $(1.5 \mathrm{~h})$, and CyclinD1 is part of the G1-S cell cycle checkpoint, Barhl2 probably acts on the length of G1 phase (Juraver-Geslin et al., 2011).

Interestingly, in the developing diencephalon, a non-apoptotic function of the effector caspase, Caspase-3, limits neuroepithelial cell proliferation by inhibiting the activation of Tcf/Lef by the $\beta$-catenin (Juraver-Geslin et al., 2011). In this context, Caspase-3 acts either in parallel, or downstream of Barhl2, and its activity does not depend on its apoptosis-effector function. In addition, in the neuroepithelium, Caspase-7 acts as the executioner Caspase leading to cell death (Sena et al., 2020). Indeed, how Barhl2 regulates Caspase- 3 non-apoptotic activity in Xenopus and limits $\beta$-catenin levels and stability in the developing diencephalon is unknown.

In conclusion, in the caudal forebrain, Barhl 2 acts as a brake on Wnt transcriptional activation, probably through the stabilization of the inhibitory Tcf/Gro complex. Barhl2 could increase the length of diencephalic progenitors' G1 phase, thereby modulating neuronal progenitors' response to extracellular signals, including those of Wnt and Shh.

\section{Wnt Signals Influence Diencephalic Barh/2 Expression}

What are the extracellular signals influencing Barhl2 expression and activity in the caudal forebrain? Wnt3a is expressed in E9.5 mice (Louvi et al., 2007) at the onset of Barhl2 expression in the same territories. Pioneer studies performed in Drosophila presented the wg pathway as a positive regulator of barhl2 expression in the notum. barhl2 expression was lost in clones mutated for Arm (reviewed in Reig et al., 2007). Conversely, the expression of a constitutively active form of arm induces an ectopic expression of barhl2 in the prescrutum, associated with a decrease of wg (Sato et al., 1999). In Xenopus, RNA-sequencing analysis revealed that both morpholinomediated depletion of Tcf711, and pharmacological activation of Wnt canonical signaling, induce an increase in barhl2 transcripts (Wills and Baker, 2015; Stevens et al., 2017).

Taken together, these observations suggest a model where Barhl 2 could be a direct, or an indirect, target of the canonical Wnt signaling pathway. In return, Barhl2 would establish a negative feedback loop that limits Wnt' activity.

\section{OTHER REGULATORS OF TCF/LEF-Gro/ TLE TRANSCRIPTIONAL ACTIVITY}

\section{Transcription Factors Binding to Tcf7l1 Influence Its Repressor Activity in a Positive And/Or Negative Way}

Beside Barhl2, other co-repressors influence Tcf7l1 inhibitory activity. Indeed, cDNA expression screens performed in mammalian cells, combined with functional analysis in Xenopus, identified 45 inducers and 96 inhibitors of Tcf/Lef activity (Freeman et al., 2015). Co-repressors' modes of action are diverse, sometimes divergent between vertebrate and invertebrate, and involve protein-protein interactions, changes in Tcf7l1 affinity for Wnt-target gene promoters, recruitment of co-repressors or co-activators, modulation of protein stability, and nuclear translocation.

CtBP, first described in Xenopus and later in rodents and human, binds to the C-terminal part of Tcf7l1-E and Tcf7l2-E isoforms. In fly, CtBP appears to be required for both activation of some Wnt targets and the repression of others, in parallel to, and independently of Tcf/Lef (Fang et al., 2006). However, the vertebrate CtBP acts as a co-factor for Tcf711, enhancing its repressor activity (Brannon et al., 1999; Xia et al., 2011). Lack of both Gro/TLE-binding domain and of the C-terminal region of Tcf7l1 leads to target genes' transcriptional activation (Gradl et al., 2002). Notably, during Xenopus SO formation, the C-terminal part of Tcf7l1, which recruits the CtBP, is not required (Liu et al., 2005). In colorectal cancer cells, TCF7l1 recruits both CtBP and HDAC1 to repress expression of the Wnt antagonist DICKKOPF4 (DKK4) (Valenta et al., 2003; Eshelman et al., 2017). Besides CtBP, Tcf7l1 directly interacts with the methyl-CpG-dependent transcriptional repressor Kaiso in Xenopus. This interaction results in their mutual disengagement from the respective DNA-binding sites in such a way that Tcf7l1 can be inhibited following Kaiso overexpression both in cell lines, and Xenopus embryos (Daniel and Reynolds, 1999). Kaiso cooperates with Tcf7l1 to repress $\beta$-catenin target genes such as sia, through epigenetic regulation (Park et al., 2005). The interaction of Kaiso with Tcf7l1 depends on Kaiso zinc-finger domains, and on the HMG-box DNA-binding domain of Tcf/Lef factors (Ruzov et al., 2009). The LIM (Lin-11, Islet-1, and Mec-3; the three original members of the family) protein HIC-5 [Hydrogen Peroxide-Induced Clone 5, also termed ARA-55 (Androgen Receptor Activator of $55 \mathrm{kDa}$ )] has been also identified as a binding partner to Tcf7l1 and Tcf7l2. Overexpression of HIC-5 acts as a negative regulator of a subset of Tcf/Lef family members, and can suppress secondary axis formation in Xenopus (Ghogomu et al., 2006). Important modulators of TCF/LEF activity are also found in the family of SOX (SRY-related HMG box) factors containing over 20 members (reviewed in Kormish et al., 2009; Bernard and Harley, 2010). In both mammalian cells and Xenopus, SOX17 and SOX4 directly bind to the HMGbox of TCF711, TCF712 and LEF1, an interaction that modulates the stability of the TCF/ $\beta$-catenin complex (Sinner et al., 2007). More recently, SOX17 was shown to functionally cooperate with $\mathrm{Wnt} / \beta$-catenin to specify an endodermal fate while repressing the meso-ectodermal fate. In this context, SOX17 and $\beta$-catenin co-occupy hundreds of key enhancers. In some cases, SOX17 and $\beta$-catenin synergistically activate transcription, apparently independently of TCF/LEF, whereas on other enhancers, SOX17 represses $\beta$-catenin/TCF-mediated transcription to 

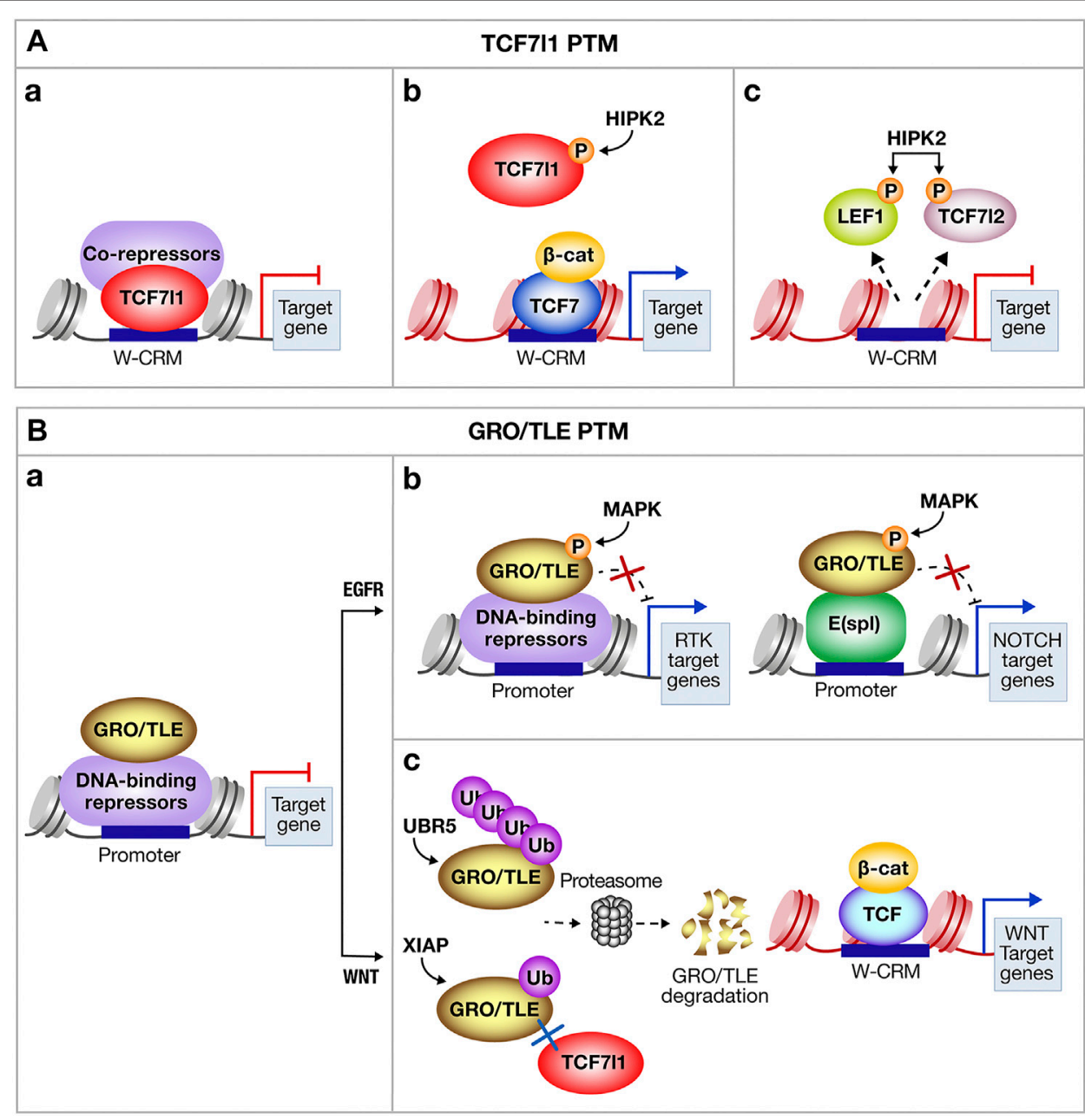

FIGURE 5 | Some Post-Translational Modifications modulating the transcriptional activities of TCF711 and Gro/TLE. Post-translational modifications (PTM) including phosphorylation and/or ubiquitination of (A) T-cell factor-like-1 (TCF711) and (B) Groucho/Transducin-like enhancer of split (Gro/TLE) influence positively, or negatively, the transcriptional output of TCF711/Gro complex. (A) (a) TCF711 bound on W-CRM with co-repressors normally limits transcription. (b) The Homeodomain-Interacting Protein Kinase-2 (HIPK2) acts as a positive or negative regulator of Wht target genes' expression. Phosphorylation of TCF711 by HIPK2 decreases TCF711 affinity to target genes' promoter and enables transcription through the $\beta$-catenin/T-Cell Factor-7 ( $\beta$-cat/TCF7) complex. (c) Conversely, phosphorylation of the transcriptional activators Lymphoid Enhancer Factor-1 (LEF1) and TCF7I2 abolishes their binding to the promoter and blocks gene transcription. (B) (a) Gro/TLE together with DNA binding Co-repressor normally limits RNA Pol II mediated transcription. (b) The Receptor Tyrosine Kinase (RTK) phosphorylates Gro/TLE through the Mitogen-Activated Protein Kinase (MAPK) pathway, resulting in a decrease of Gro/TLE repressive activity. Gro/TLE mediates crosstalk between Notch and MAPK signaling pathways. Notch signaling activation leads to the expression of the Enhancer of split E(spl), which is a major transcriptional repressor of Notch target genes. E(spl) complexes with Gro/TLE to block target genes' expression, including proneural genes. Phosphorylation of Gro/TLE by the MAPK pathway inhibits its function as a repressor. (c) When Wnt signaling is activated, the E3 ubiquitin ligase (UBR5) polyubiquitinates Gro/TLE in flies. Similarly, in vertebrate, the X-linked Inhibitor of Apoptosis (XIAP) is recruited to the transcriptional complex containing TCF7I1 and Gro/TLE, and monoubiquitinates Gro/TLE. Mono/polyubiquitination of Gro/TLE enables its degradation by the proteasome and blocks its re-association to TCF711, allowing the recruitment of the transcriptional co-activator $\beta$-cat to the activating TCF/LEF, and further expression of Wnt target genes. W-CRM, WntCis regulatory motif; EGFR, Epidermal Growth Factor Receptor.

spatially restrict gene expression domains. In this context, SOX17 acts as a tissue-specific modifier of the TCF/LEF responses (Mukherjee et al., 2021). Another modulator of the canonical Wnt signaling is SOX9, which was found to associate with $\beta$-catenin and further inhibit its activity (Topol et al., 2009). Further observations show that SOX9 proteins, together with Krüppel-like factor 4 (KLF4), suppress the Wntinduced transcription through competing with TCF/LEF for the same $\beta$-catenin promoter sites, inhibiting the $\beta$-catenin-TCF/LEF (more specifically TCF712) binding and transcriptional activity (Sellak et al., 2012).

\section{Post-Translational Modifications Influence Both TCF/LEF and Gro/TLE Interactions}

Besides the spatial and temporal distribution of repressor partners, PTM, including ubiquitination and/or phosphorylation of TCF/LEF and Gro/TLE, influence 
positively or negatively, Gro/TLE-TCF/LEF interactions (reviewed in Cinnamon et al., 2008; Turki-Judeh and Courey, 2012; Ramakrishnan et al., 2018). In gastrulating Xenopus embryos and in mammalian cells, phosphorylation of TCF7l1 by the Homeodomain Interacting Protein Kinase 2 (HIPK2) inhibits its capacity to bind its target genes (Figure 5A). $\beta$-catenin was found to serve as a scaffold that promotes HIPK2 interaction with TCF711 and the subsequent dissociation of TCF7l1 from the target gene promoter, thereby opening the way for $\beta$-catenin interaction with the non-phosphorylated TCF7, and activation of Wnt target genes' transcription (Figure 5Ab). Mutated TCF7l1 proteins resistant to Wnt-dependent phosphorylation function as constitutive inhibitors. HIPK2-dependent phosphorylation also causes the dissociation of LEF1 and TCF712 from their targets' promoter (Figure 5Ac) and its effect is thereby highly context specific: HIPK2 up-regulates transcription by phosphorylating TCF7l1, a transcriptional repressor, but inhibits transcription by phosphorylating LEF1, a transcriptional activator (Hikasa et al., 2010; Hikasa and Sokol, 2011). Alternatively, in mouse embryonic stem cells (mESCs), $\beta$-catenin inactivates TCF7l1 by removing it from DNA, which is followed by TCF7l1 protein degradation. Interestingly, in this context, genetic cues indicate that TCF711 inactivation appears to be the only required effect of the TCF711/ $\beta$-catenin interaction (Shy et al., 2013).

Gro/TLE co-repressors are targets of PTM, which modulate their affinity not only for Wnt effectors, but also Notch, and Epidermal Growth Factor Receptor (EGFR) signaling cascades (Figure 5B). One example comes from studies in Drosophila demonstrating that EGFR signaling, mediated via the Mitogen-Activated Protein Kinase (MAPK), phosphorylates Gro/TLE, and leads to the weakening of its repressor function, and attenuation of Gro/TLE-dependent transcriptional silencing by the $\mathrm{E}(\mathrm{spl})$ proteins, which are the effectors of the Notch cascade (Figure 5Bb). Reversibly, when RAS/MAPK signaling is impeded, Gro/TLE-mediated repression is enhanced both in vitro and in vivo. Thus, downregulation of Gro/ TLE-dependent repression by MAPK modulates the transcriptional output of the Notch pathway, and possibly of other pathways (reviewed in Cinnamon et al., 2008). In both Drosophila and human cell lines, the E3 ubiquitin ligase UBR5 is required for Wnt cellular response. In this context, Wnt signaling induces the ubiquitination of Gro/TLE by UBR5, which happens downstream of $\beta$-catenin stabilization (Figure 5Bc). In vivo observations argue that ubiquitination inactivates Gro/TLE, thereby enabling Arm/ $\beta$-catenin to activate transcription (Flack et al., 2017). Interestingly, inactivation of Gro3/TLE3 occurs via the activity of AAA ATPase Valosin-containing protein (VCP, also known as p97). VCP unfolds ubiquitinated proteins via its ATPase activity and disrupts ubiquitinated Gro3/TLE3 tetramerization, a process required for Gro/TLE to repress Wnt targets (Chodaparambil et al., 2014). Moreover mono-ubiquitination of Gro3/TLE3 by the E3 ubiquitin ligase XIAP (X-linked Inhibitor of Apoptosis) at its N-terminal Q-rich domain disrupts the ability of Gro3/TLE3 to bind TCF7l1, and consequently inhibits TCF711 repressor activity. XIAP is recruited to the Gro/TCF complex upon Wnt pathway activation, which enhances $\beta$-catenin/TCF complex assembly and the initiation of a Wnt-specific transcriptional activation program (Hanson et al., 2012). Because UBR5 and XIAP ubiquitinate Gro3/TLE3 in distinct ways (poly vs. mono) and at different locations on the Gro3/TLE3 protein, it is possible that the two E3 ligases modulate the Wnt transcriptional switch either in parallel, or simultaneously, depending on the cellular context. In addition to its ubiquitination activity, XIAP has been shown to play a role in inhibiting Caspases. In vertebrate, XIAP directly binds to and functionally blocks Caspase-3, Caspase-7 and Caspase- 9 proteolytic activity (reviewed in Liston et al., 2003). However, there is no evidence for the XIAP-mediated degradation of vertebrate Caspases in vivo, which appears to depend on the type of ubiquitination and on the cell type.

\section{Evolutionary Conservation of BARHL Protein's Structure and Functions}

As previously described, BARHL1 and BARHL2 proteins have a strong degree of homology between one another. BARHL2 is highly conserved amongst distant species in the evolutionary scale, as observed through the high aa sequence conservation throughout its entire sequence (Figure 4). Besides, they are amongst the TFs essential for patterning the body axis of the developing embryo that are conserved in simpler organisms beyond the phylum of chordates. For example, genetic programs ancestral to the ones required for vertebrate development were found conserved in hemichordates. In S. kowalevskii, which is thought to be the closest species to the common ancestor at the base of the phylogenetic tree of chordates, Barhl2 ortholog gene shares close similarities in its distribution and expression patterns compared to chordates (reviewed in Röttinger and Lowe, 2012; Sena et al., 2016). A conserved Shh Brain Enhancer (SBE1) has been discovered in mice with an equivalent function to that described in the $S$. kowalevskii. SBE1 directly regulates Shh expression in the zli through binding the second intron of the Shh gene. Diverse transcription factors, including Otx2 and Barhl2, directly regulate SBE1 within the zli. Functional analysis in both species demonstrated sufficient conservation between Barhl2 and one of the S. kowalevskii barH HD for both binding, and activating CRM, thereby controlling Shh expression (Yao et al., 2016) (reviewed in Sena et al., 2016).

In C. elegans, the cephalic chemosensory neurons (CEM) undergo PCD during hermaphrodite embryogenesis but not in males (Sulston et al., 1983), a process relying on CEH30, a BarHD transcription factor (Schwartz and Horvitz, 2007). CEH30 protein interacts with UNC-37, which is the C. elegans homologue of Gro/TLE, through its N-terminal EH1 motif. It thereby prevents cell death (Peden et al., 2007) and inhibits transcription of egl-1 gene, which encodes the executioner cell death protein CED-3, one of the major components of the PCD in worm (Nehme et al., 2010). Sequence comparison between human BARHL2 and CEH-30 proteins reveals $64 \%$ identical amino acids in the region including the $\mathrm{HD}$ and the motif immediately next to the $\mathrm{HD}$ on the C-terminal side called the BARC motif (Bar homeodomain C-terminal motif) (Figure 4). Interestingly, murine Barhl1 or Barhl2 genes compensate for the loss of function of CEH-30 in C. elegans (Schwartz and Horvitz, 2007), which is consistent with a conservation of Barhl genes' function through evolution. 


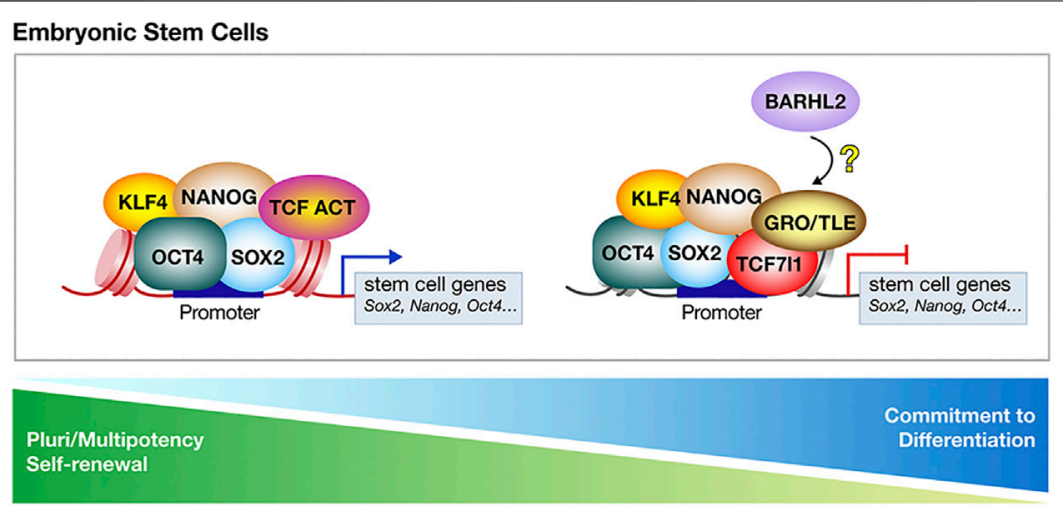

FIGURE 6 | TCF7l1-mediated repression is at play in committed mouse embryonic stem cells (mESCs). In mESCs, the T-Cell Factor/Lymphoid Enhancer Factor (TCF/LEF) switch from a transcriptional activator to inhibitor, controls the balance between pluripotency and differentiation. Key pluripotency genes Octamer-binding transcription factor-4 (OCT4), SRY-box 2 (SOX2), NANOG and Krüppler-like factor-4 (KLF4) mark the pluripotent state of mESCs and are associated with the coactivators TCF7. In mESCs, TCF7I1 is the most expressed member of the Tcf/Lef family. TCF7I1 associates with regulatory regions that are bound by OCT4, SOX2, NANOG, and KLF4. Through interacting with Groucho/Transducin-like enhancer of split (Gro/TLE), TCF7I1 inhibits the expression of "stem cells" genes and allows mESCs to differentiate. Eliminating TCF7l1 repressive activity on mESCs pluripotency network allows the reacquisition of pluripotency and self-renewal. BARHL2 is expressed in mESCs during their commitment phase and could participate in driving mESCs towards irreversible commitment and differentiation by blocking TCF7I1 in a transcriptional inhibitory state.

\section{THE CORE ROLE OF TCF7L1 AS A TRANSCRIPTIONAL INHIBITOR IN DRIVING EMBRYONIC AND NEURAL STEM CELLS TOWARDS DIFFERENTIATION}

\section{In Mouse Embryonic Stem Cells, Inhibition of TCF711-Mediated Repression Promotes Self-Renewal and Pluripotency}

$\mathrm{mESC}$ isolated from the inner cell mass of the blastocyst, the preimplementation stage mammalian embryo, are characterized by their ability to self-renew and to differentiate into all types of somatic cells, a process referred to as pluripotency (reviewed in Chen et al., 2017). A specific core set of transcription factors including OCT4 (Octamer-binding transcription factor 4), NANOG, SOX2 and KLF4 form regulatory circuitry consisting of autoregulatory and feedforward loops thereby supporting pluripotency and self-renewal of these cells (Boyer et al., 2005). Extracellular signaling including LIF/JAK/STAT3 (Leukemia Inhibitory Factor/Janus Kinase/Signal Transducer and Activator of Transcription) (Williams et al., 1988; Ying et al., 2008), Wnt (Hao et al., 2006; ten Berge et al., 2011), BMP (Ying et al., 2003), and the MAPK/ERK (Yang et al., 2012) cascades, influence mESCs fate decision. Indeed, in mESC, Wnt signaling has been demonstrated to have important, somewhat difficult to interpret, activities (reviewed in Niwa, 2011; Merrill, 2012). From all these studies, a consensus emerges that inhibition of TCF7l1-mediated repression is at the core of mESC selfrenewal and pluripotency (Figure 6) (Atlasi et al., 2013) (reviewed in Sokol, 2011; Wray and Hartmann, 2012). Reversibly, enhancement of TCF7l1 repressive activity blocks mESC self-renewal, and allows mESCs to differentiate, even in the presence of Wnt signaling (Wray et al., 2011).
In mESCs, TCF711 is the most expressed member among the TCF/LEF protein family (Pereira et al., 2006; Salomonis et al., 2010). Whole-genome approaches including RNA-seq and ChIP-seq show that TCF7l1 transcriptionally represses many genes important for maintaining pluripotency, and self-renewal, as well as those involved in lineage commitment, and stem cell differentiation. TCF7l1 associates with the regulatory regions of 1369 genes (Tam et al., 2008). Among those regions, 1173 bind TCF7l1 and OCT4 (Cole et al., 2008) with more than 940 binding TCF7l1, OCT4, SOX2, and NANOG (Boyer et al., 2005; Pereira et al., 2006; Marson et al., 2008). Depletion of TCF7l1 generates mESC' refractory to differentiation (Cole et al., 2008). Moreover, both the Gro/TLE and CtBP interacting domains of TCF7l1 are required for OCT4 repression (Tam et al., 2008). Finally, KLF4 gene contains conserved TCF/LEF binding sites, and its expression is downregulated by TCF7l1 (Park et al., 2015). Interestingly, two TCF7l1 isoforms have been discovered, and are expressed equally in mESCs, where they regulate both an overlapping, as well as different sets of target genes. Removal of one of both TCF7l1 isoforms was found sufficient to stimulate self-renewal and delay the differentiation through repression of NODAL and KLF4 (Salomonis et al., 2010). Further analysis revealed that binding of $\beta$-catenin to both TCF7l1 and TCF7 contributes to the maintenance of self-renewal and gene expression, at least partly through their recruitment to OCT4binding sites on ESC chromatin (Yi et al., 2011).

The crucial role of TCF7l1 is reinforced by analysis of mESCs lacking all full-length TCF/LEF. In such cells, re-expression of TCF711 makes mESCs capable of differentiating into the three lineages, including neuronal cells (Moreira et al., 2017). In this context, TCF711 has been shown to directly interact with OCT4, and compete with SOX2 at some SOX-CRM, a process under the influence of MEK/MAPK (Zhang et al., 2013). Indeed, besides limiting TCF711-mediated repression of the pluripotency network, inhibition of the MAPK/ERK pathway participates in 
maintenance of pluripotency and self-renewal (reviewed in de Jaime-Soguero et al., 2018). In mESCs, inhibition of MEK suppresses LEF1 expression, and depletion of LEF1 partially mimics the self-renewal-promoting effect of MEK inhibitors. In the absence of the exogenous factors, cytokines or inhibitors, depletion of both TCF7l1 and LEF1 enables maintenance of undifferentiated mESCs (Ye et al., 2017).

In agreement with all these data, Gro/TLE, more specifically Gro4, is not required for sustaining pluripotency, and suppressing differentiation genes in mESC. Rather, Gro/TLE activity appears necessary for early differentiation where it acts to suppress the pluripotency network, allowing for the initiation of lineage specific gene expression programs. In mESCs, most of the genes occupied by TCF7l1 were found co-occupied by Gro/TLE (Laing et al., 2015). Through interacting with Gro/TLE, TCF711 represses NANOG (Pereira et al., 2006), and repression of OCT4 was found to rely on TCF7l1/Gro2 interactions (Tam et al., 2008). Interestingly, the dominant-negative GRG5 is highly expressed in mESC, and its expression drops once mESCs exit the pluripotent state, to increase again during neuroectodermal cell specification. Whereas overexpression of GRG5 promotes self-renewal, its siRNA-mediated $\mathrm{KD}$ deregulates the $\mathrm{mESC}$ pluripotent state. Transcriptomic analysis reveals that, in this context, GRG5 represses mesendodermal-related genes, and promotes neuronal specification via inhibition of Wnt and BMP signaling. Moreover, GRG5 maintains the self-renewal of NSCs by sustaining the activity of Notch/HES and STAT3 signaling pathways (Chanoumidou et al., 2018).

In contrast to what is reported in $\mathrm{mESC}$, in human ESC (hESCs), Wnt/ $\beta$-catenin signaling appears to be actively repressed in an OCT4-dependent manner during self-renewal. In these cells, activation of Wnt signaling appears to induce loss of self-renewal, and differentiation into mesodermal lineages (Davidson et al., 2012). Although such discrepancy is a little puzzling, it has been shown that generation of neural lineages from hESCs requires inhibition of Wnt signaling (Tabar and Studer, 2014) and that activation of Wnt signaling in hESCsderived neural precursor cells promotes transcription of midbrain-like genes through TCF712 directly binding the Engrailed-1 (EN1) promoter (Kim et al., 2018).

\section{The Case of Neural Stem Cells During Development}

Besides its role in development of the CNS, Wnt/ $\beta$-catenin signaling is crucial for NSCs maintenance. NSCs emerge from territories that have kept their neuroepithelium properties and respond to Wnt signals from embryogenesis through adulthood (Selvadurai and Mason, 2011; Garbe and Ring, 2012; Borday et al., 2018). In the subventricular zone of the developing mouse brain, Wnt signaling is a hallmark of self-renewing, specifically of NSCs' (Kalani et al., 2008). Investigation of the developmental fate of Wnt/ $\beta$-catenin-responsive cells in embryonic and postnatal mouse brain using a reporter for Axin2, demonstrates the continued importance of persistent Wnt $/ \beta$-catenin signaling for NSCs and progenitor cells emergence (Bowman et al., 2013). In mouse adult hippocampus, where new neurons are continuously generated from NSCs, expression of the pro-neural TF Neurogenic Differentiation 1
(NEUROD1) is a landmark of cells dropping out of self-renewal and entering neuronal commitment. Overlapping binding sites for the TCF/LEF factors and SOX2, a marker of most uncommitted cells of the CNS, are present in the promoter region of Neurod1. In this context, Wnt signaling together with removal of SOX2 triggers the expression of NEUROD1, demonstrating that the SOX2-TCF/LEF regulatory elements are critical for NEUROD1 expression, and consequently for the switch from the SOX2-mediated repression to the TCF/LEF-mediated activation, towards a neuronal fate ((Kuwabara et al., 2009). In neural precursor cells of the mouse' neocortex, expression of TCF7l1 was found to repress Wnt activity (Ohtsuka et al., 2011; Kuwahara et al., 2014), and active Wnt signaling in the rodents' neocortex apical progenitors sustain their fate plasticity (Oberst et al., 2019). In cultured rat adult hippocampal NSCs, fate decision is influenced by the temporal variations of $\beta$-catenin. Optogenetic approaches reveal that continuous activation of $\beta$-catenin in cultured NSCs specifies neuronal differentiation, whereas short $\beta$-catenin signals activate proliferation but remain insufficient to induce neuronal differentiation. Loss of $\beta$-catenin signals promotes apoptosis in differentiating cells, which could be due to inappropriate cellcycle re-entry (Rosenbloom et al., 2020).

\section{BARHL2 Promotes mESCs Differentiation}

Does BARHL2 play a part in mESC biology via its ability to enhance TCF7l1 repressive activity? Although such a question has not been directly asked, it is known that BARHL2 is expressed in mESCs during their commitment phase (Lee et al., 2006). Global expression profile analysis of $\mathrm{mESC}$ lines in which BARHL2 overexpression was induced in a doxycycline-controllable manner, reveals that BARHL2 induces a significant fold-change in more than three thousand genes with more than two thousand genes being upregulated, and more than one thousand genes downregulated. In this context, BARHL2 was one of the most influential TF analyzed. Two days following BARHL2 induction, mESCs start to express mesodermal lineage markers (Yamamizu et al., 2016). In a study using another BARHL2 overexpression design in mESCs, a significant increase in the population of neural cells was observed 14 days post-induction (Teratani-Ota et al., 2016). In this context, Notch signaling pathway played a significant influence in driving neural differentiation, and the majority of neuron-like cells generated by induction of BARHL2 expressed markers of GABAergic neurons.

Work is still needed to understand the context-specific regulation of TCF/LEF activities in the biology of ESC, specifically in hESCs. However, studies from the last 15 years strongly support inhibition of TCF711-repression as the necessary downstream effect of Wnt signaling in the promotion of mESCs' self-renewal and pluripotency. Reversibly, the formation and stabilization of the TCF711/Gro complex, and its inhibitory influence on specific chromatin loci, is one of the crucial switches driving ESCs towards cellular commitment (reviewed in Sokol, 2011). Genetic and functional studies demonstrated that the Gene Regulatory Networks (GRN) underlying acquisition/ loss of the pluripotent state are similar in the rodent, fish, and amphibian's blastomeres, and in mESCs, with slight differences observed in hESCs. In early blastomeres, BARHL2-mediated lock of TCF711 in an inhibitory state pushes early SO cells towards 
irreversible commitment and differentiation, arguing for a similar function in mESCs.

\section{Wnt Signaling Deregulation and Stem Cells: The Emergence of Cancer}

In the past years, an increasing number of studies have demonstrated that mutations, loss, or aberrant regulation of Wnt signaling are at the origin of a wide variety of diseases (reviewed in Noelanders and Vleminckx, 2017; Ng et al., 2019). In one of its severest forms, Wnt constitutive activation is associated with diverse cancer types including melanoma, leukemia, breast cancer, gastro-intestinal cancers, and others (reviewed in Zhan et al., 2017). Cancer Stem Cells (CSCs), also known as Tumor Initiating Cells (TICs), are characterized by their "stemness" characteristics that contribute to tumor progression and drug resistance and play deterministic roles in cancer recurrence. Cancer cells exhibit many of the same features as stem cells including self-renewal and their low level of differentiation. Whereas the exact connection between cancer and stem cells is not completely understood, it is well established that both cells use similar signaling pathway machineries, specifically those of the Wnt/ $\beta$-catenin, Shh, MAPK/ERK and Notch pathways (reviewed in Friedmann-Morvinski and Verma, 2014). In this section, we focus on the impact of Wnt signaling on CSCs, and on medulloblastoma $(\mathrm{MB})$, a pediatric tumor of cerebellar origins in which contributions of both TCF/LEF and the BARHLs are relevant.

\section{Wnt and Cancer Stem Cells}

As observed through activity of a TCF/LEF reporter gene, Wnt/ $\beta$-catenin signaling is highly active in various types of CSCs including colon, lung, breast, and gastric cells (Vermeulen et al., 2010; Horst et al., 2012). A pharmacological antagonist of $\beta$-catenin/TCF7l2 interaction blocks CSCs' self-renewal and suppresses tumorigenesis. Treatment of human colon cancer cells, and mouse salivary gland cells with such compound did not only reduce the $\beta$-catenin/TCF712-mediated proliferation rate and self-renewal, but also induced the differentiation of tumor cells (Fang et al., 2016), making it a potential therapeutic target of the $\beta$-catenin-TCF/LEF-dependent tumors, among other tested drugs (reviewed in Jung and Park, 2020; Walcher et al., 2020; Zhang and Wang, 2020). Non-coding RNAs have also been identified as modulators of Wnt-TCF/LEF activity in CSCs. For example, miR-142, which is absent in normal mammary cells but highly expressed in mammary CSCs, increases Wnt activity by inducing degradation of APC, a negative regulator of canonical Wnt signaling (Isobe et al., 2014). Additionally, the long non-coding RNA IncTCF7 has been characterized in hepatocellular carcinoma cells. IncTCF7 maintains CSCs' properties via TCF7-dependent activation of Wnt signaling (Wang et al., 2015). Notably, the ability of both normal and CSCs to maintain long telomeres - an important feature to prevent their cellular aging - appears to be under direct transcriptional control of $\beta$-catenin-TCF/LEF (Park et al., 2009; Noureen et al., 2021). Whereas the promoter of the telomerase enzymatic subunit, TERT, neither bind TCF712 nor
TCF711, it is enriched with TCF7-binding sites located close to the transcription start site that binds $\beta$-catenin specifically (Hoffmeyer et al., 2012).

\section{Medulloblastoma}

Medulloblastoma (MB), the most common childhood malignant brain tumor, emerges from the cerebellum and accounts for $30 \%$ of pediatric brain tumors. Integrated genomic studies allowed the identification of four types of human $\mathrm{MB}$, corresponding to specific genetic alterations (reviewed in Hatten and Roussel, 2011; Wang et al., 2018). One group is associated with alterations in the $\mathrm{Wnt} / \beta$-catenin signaling pathway $(15 \%$ of the cases) and originates from brain stem cells. A second group ( $25 \%$ of the cases) is characterized by the constitutive activation of the Shh pathway and derives from Granule Neuron (GN) progenitors. Group 3 (30\% of the cases) is specifically found in infants and is thought to originate from overexpression of the MYC oncogene in cerebellar NSCs. Whereas group 4 is the most common $\mathrm{MB}$ subgroup ( $30 \%$ of the cases), its underlying biology is not well understood.

In the rodent brain, the cerebellar upper Rhombic Lip (uRhL) produces the GNs that constitute the largest neuronal population in the brain. The GN population exhibits a unique developmental trait: committed GN progenitors (GNPs) are characterized by a very long period of "quiescence" occurring before birth, followed by a long proliferative phase - i.e., 2 weeks in mouse, 2 years in human - occurring after birth, before their final differentiation step (reviewed in Leto et al., 2016). Due to this developmental specificity, this cell population is at risk when it comes to the appearance of developmental defects, including oncogenic events (reviewed in Hatten and Roussel, 2011). At birth, the RhL stem/ progenitor cells become responsive to secreted $\mathrm{SHH}$ that stimulates their proliferation and self-renewal. The $\mathrm{uRhL}$ exhibits stem cell niche properties and exhibit positive TCF/ LEF transcriptional activity (Selvadurai and Mason, 2011; Bowman et al., 2013; Yeung et al., 2014; Borday et al., 2018). Atonal Homologue 1 (ATOH1/MATH1) is the master gene of GNPs' development (reviewed in Leto et al., 2016). ATOH1 directly induces the expression of Barhl1 and Barhl2 (Kawauchi and Saito, 2008). A thorough single-cell RNA-seq performed on mouse cerebellar cells reveals that Tcf7l1 is expressed strongly early in the GNPs' differentiation pathway (Wizeman et al., 2019), and that Barhl2 expression is uniquely associated with early fate commitment in the GNPs (Carter et al., 2018). Taken together, these observations argue that BARHL2 could participate in driving GN stem/progenitor cells towards irreversible commitment.

Rodent cerebellar uRhL cells are known to be at the origin of group $2 \mathrm{MB}$ that are associated with deregulation of the Shh pathway (reviewed in Hovestadt et al., 2020; Garcia-Lopez et al., 2021). Some tumor-propagating cells from this subgroup are not only resistant to Shh inhibitors but are also TCF/LEF-dependent for their self-renewal (Rodriguez-Blanco et al., 2017). in silico analysis associates $B A R H L 2$ expression with the emergence of group $2 \mathrm{MB}$, and $B A R H L 1$ expression with emergence of group 3 and group $4 \mathrm{MB}$ (Pöschl et al., 2011; Lin et al., 2016). Taken together, these observations are a good starting point for future 
research that should evaluate whether BARHLs act as roadblocks for de-differentiation that are corrupted in MB.

\section{CONCLUSION AND PERSPECTIVES}

In this review, we provide an overview of the TCF/LEF activities as transcriptional repressors focusing on the highly evolutionarily conserved roles of Wnt signaling in axis establishment, neural proliferation, and stem cell biology. We also described the importance of the pro-neural TF BARHL2 as an enhancer of TCF7L1 repressor activities in both SO formation, and forebrain progenitor proliferation.

Currently, numerous conundrums regarding the developmental regulation(s) of TCF/LEF activities, including their interactions with the Barhls, are unresolved. An important point is to clarify the interactions between Barhl2, and generally the Barhls, with the different TCF/LEF members: which Barhl interacts with each of the TCF/LEF family? Are these interactions specific to the different TCF/LEF isoforms and their splice variants? What characterizes the TCF/LEF-BARHL binding interface? Is the interface evolutionarily conserved? Numerous signaling pathways interplay to orchestrate the multipotency/commitment/proliferation states of neural stem/ progenitor during embryogenesis. Besides Wnt signaling, the activation and/or inhibition of TCF/LEF activity is under the influence of Notch, Shh, and MAPK/ERK pathways. The context, the repression partners, and the PTM involved in controlling these subtle levels of regulation in NSCs are still poorly understood. Exploration of Barhl2 developmental expression indicates that it is either a direct, or an indirect, target of the canonical Wnt signaling pathway, thereby contributing to the establishment of a negative feedback loop, that limits the TCF/ LEF transcriptional activity in neural progenitors. Analysis of TCF/LEF activity in pluripotent versus committed ESCs indicate that TCF/LEF mostly act by changing the chromatin state in such a way that the expression of the pluripotency-related genes is switched off (reviewed in Sokol, 2011). As BARHL2 blocks TCF7L1 in a transcriptional inhibitory state, it is tempting to speculate that BARHL2 participates to driving stem/progenitor cells towards irreversible commitment, thereby establishing a roadblock on the cell trajectory towards differentiation.

\section{REFERENCES}

Adamska, M., Larroux, C., Adamski, M., Green, K., Lovas, E., Koop, D., et al. (2010). Structure and Expression of Conserved Wnt Pathway Components in the Demosponge Amphimedon Queenslandica. Evol. Develop. 12, 494-518. doi:10.1111/j.1525-142X.2010.00435.x

Afouda, B. A., Nakamura, Y., Shaw, S., Charney, R. M., Paraiso, K. D., Blitz, I. L., et al. (2020). Foxh1/Nodal Defines Context-specific Direct Maternal Wnt/ $\beta$-Catenin Target Gene Regulation in Early Development. iScience 23, 101314. doi:10.1016/j.isci.2020.101314

Alvarez-Medina, R., Cayuso, J., Okubo, T., Takada, S., and Marti', E. (2008). Wnt Canonical Pathway Restricts Graded Shh/Gli Patterning Activity Through the Regulation of Gli3 Expression. Development 135, 237-247. doi:10.1242/dev.012054
Another important unresolved question relates to how BARHL2, TCF/LEF and Gro/TLE act long distance to transcriptionally inhibit key "commitment" genes. Understanding the specificity of BARHL2 DNA-binding alone, or together with TCF/LEF, should be a first step in identifying the set of genes whose expression is silenced via BARHL2/TCF7L1 activity. Moreover, understanding how the BARHL2/TCF7L1 modulates the open/close state of the chromatin, together with probable roles of PTM on the complex stability and its transcriptional activity, shall prove quite beneficial beyond understanding early embryogenesis. Finally, in both amphibian, and rodent, Barhl2 participates in the formation of the caudal forebrain organizer, partly through its direct activation of Shh transcription together with Otx2 (Yao et al., 2016) (reviewed in Sena et al., 2016). Thereby, BARHL2's function is not strictly restricted to its activity as a Wnt transcriptional repressor, but probably depends on the cellular context, adding another level of complexity that should be taken into consideration.

\section{AUTHOR CONTRIBUTIONS}

JB-R and BD wrote the manuscript and drafted the figures.

\section{FUNDING}

$\mathrm{BD}$ is funded by the Centre National de la Recherche Scientifique (CNRS UMR 7622). JB-R is supported by a fellowship from the "Ministère de la Recherche." The work was supported by the Centre National de la Recherche Scientifique (CNRS UMR7622), Sorbonne Université, Fondation Pierre Gilles de Gennes (FPGG0039), Ligue Nationale contre le Cancer Comité Ile de France (RS19/75-52) and private donors to BD project. Money from private donors was used to pay for the open access publication fees.

\section{ACKNOWLEDGMENTS}

The authors greatly acknowledge Sophie Gournet (IBPS, CNRS -UMR7622) for the illustrations, Paul Johnson and Pamela Waked for editing the manuscript content.

Anderson, C., and Stern, C. D. (2016). Organizers in Development. Curr. Top. Dev. Biol. 117, 435-454. doi:10.1016/bs.ctdb.2015.11.023

Andoniadou, C. L., and Martinez-Barbera, J. P. (2013). Developmental Mechanisms Directing Early Anterior Forebrain Specification in Vertebrates. Cell. Mol. Life Sci. 70, 3739-3752. doi:10.1007/s00018-013-1269-5

Arce, L., Pate, K. T., and Waterman, M. L. (2009). Groucho Binds Two Conserved Regions of LEF-1 for HDAC-dependent Repression. BMC Cancer 9, 159. doi:10.1186/1471-2407-9-159

Atcha, F. A., Munguia, J. E., Li, T. W. H., Hovanes, K., and Waterman, M. L. (2003). A New $\beta$-Catenin-dependent Activation Domain in T Cell Factor. J. Biol. Chem. 278, 16169-16175. doi:10.1074/jbc.M213218200

Atcha, F. A., Syed, A., Wu, B., Hoverter, N. P., Yokoyama, N. N., Ting, J.-H. T., et al. (2007). A Unique DNA Binding Domain Converts T-Cell Factors into Strong Wnt Effectors. Mol. Cel Biol 27, 8352-8363. doi:10.1128/MCB.02132-06 
Atlasi, Y., Noori, R., Gaspar, C., Franken, P., Sacchetti, A., Rafati, H., et al. (2013). Wnt Signaling Regulates the Lineage Differentiation Potential of Mouse Embryonic Stem Cells Through Tcf3 Down-Regulation. Plos Genet. 9, e1003424. doi:10.1371/journal.pgen.1003424

Bernard, P., and Harley, V. R. (2010). Acquisition of SOX Transcription Factor Specificity through Protein-Protein Interaction, Modulation of Wnt Signalling and Post-translational Modification. Int. J. Biochem. Cel Biol. 42, 400-410. doi:10.1016/j.biocel.2009.10.017

Bhambhani, C., Ravindranath, A. J., Mentink, R. A., Chang, M. V., Betist, M. C., Yang, Y. X., et al. (2014). Distinct DNA Binding Sites Contribute to the TCF Transcriptional Switch in C. elegans and Drosophila. Plos Genet. 10, e1004133. doi:10.1371/journal.pgen.1004133

Billin, A. N., Thirlwell, H., and Ayer, D. E. (2000). $\beta$-Catenin-Histone Deacetylase Interactions Regulate the Transition of LEF1 from a Transcriptional Repressor to an Activator. Mol. Cel Biol 20, 6882-6890. doi:10.1128/MCB.20.18.68826890.2000

Blauwkamp, T. A., Chang, M. V., and Cadigan, K. M. (2008). Novel TCF-Binding Sites Specify Transcriptional Repression by Wnt Signalling. EMBO J. 27, 1436-1446. doi:10.1038/emboj.2008.80

Blythe, S. A., Cha, S.-W., Tadjuidje, E., Heasman, J., and Klein, P. S. (2010). $\beta$-Catenin Primes Organizer Gene Expression by Recruiting a Histone H3 Arginine 8 Methyltransferase, Prmt2. Develop. Cel 19, 220-231. doi:10.1016/ j.devcel.2010.07.007

Borday, C., Parain, K., Thi Tran, H., Vleminckx, K., Perron, M., and MonsoroBurq, A. H. (2018). An Atlas of Wnt Activity During Embryogenesis in Xenopus Tropicalis. PLoS ONE 13, e0193606. doi:10.1371/ journal.pone.0193606

Bowman, A. N., van Amerongen, R., Palmer, T. D., and Nusse, R. (2013). Lineage Tracing with Axin2 Reveals Distinct Developmental and Adult Populations of Wnt/-Catenin-Responsive Neural Stem Cells. Proc. Natl. Acad. Sci. 110, 7324-7329. doi:10.1073/pnas.1305411110

Boyer, L. A., Lee, T. I., Cole, M. F., Johnstone, S. E., Levine, S. S., Zucker, J. P., et al. (2005). Core Transcriptional Regulatory Circuitry in Human Embryonic Stem Cells. Cell 122, 947-956. doi:10.1016/j.cell.2005.08.020

Brafman, D., and Willert, K. (2017). Wnt/ $\beta$-catenin Signaling during Early Vertebrate Neural Development. Devel Neurobio 77, 1239-1259. doi:10.1002/dneu.22517

Brannon, M., Brown, J. D., Bates, R., Kimelman, D., and Moon, R. T. (1999). XCtBP Is a XTcf-3 Co-repressor with Roles Throughout Xenopus Development. Development 126, 3159-3170. doi:10.1242/dev.126.14.3159

Brannon, M., Gomperts, M., Sumoy, L., Moon, R. T., and Kimelman, D. (1997). A Beta -catenin/XTcf-3 Complex Binds to the Siamois Promoter to Regulate Dorsal Axis Specification in Xenopus. Genes Develop. 11, 2359-2370. doi:10.1101/gad.11.18.2359

Brantjes, H. (2001). All Tcf HMG Box Transcription Factors Interact with Groucho-Related Co-repressors. Nucleic Acids Res. 29, 1410-1419. doi:10.1093/nar/29.7.1410

Brown, D. D. R., Molinaro, A. M., and Pearson, B. J. (2018). The Planarian TCF/ LEF Factor Smed-Tcf1 Is Required for the Regeneration of Dorsal-Lateral Neuronal Subtypes. Develop. Biol. 433, 374-383. doi:10.1016/ j.ydbio.2017.08.024

Bulfone, A. (2000). Barhl1, A Gene Belonging to a New Subfamily of Mammalian Homeobox Genes, Is Expressed in Migrating Neurons of the CNS. Hum. Mol. Genet. 9, 1443-1452. doi:10.1093/hmg/9.9.1443

Calvo, D., Victor, M., Gay, F., Sui, G., Po-Shan Luke, M., Dufourcq, P., et al. (2001). A POP-1 Repressor Complex Restricts Inappropriate Cell Type-specific Gene Transcription During Caenorhabditis elegans Embryogenesis. EMBO J. 20, 7197-7208. doi:10.1093/emboj/20.24.7197

Canon, J. (2003). In Vivo Analysis of a Developmental Circuit for Direct Transcriptional Activation and Repression in the Same Cell by a Runx Protein. Genes Develop. 17, 838-843. doi:10.1101/gad.1064803

Carnac, G., Kodjabachian, L., Gurdon, J. B., and Lemaire, P. (1996). The Homeobox Gene Siamois Is a Target of the Wnt Dorsalisation Pathway and Triggers Organiser Activity in the Absence of Mesoderm. Development 122, 3055-3065. doi:10.1242/dev.122.10.3055

Carter, R. A., Bihannic, L., Rosencrance, C., Hadley, J. L., Tong, Y., Phoenix, T. N., et al. (2018). A Single-Cell Transcriptional Atlas of the Developing
Murine Cerebellum. Curr. Biol. 28, 2910-2920. doi:10.1016/ j.cub.2018.07.062

Castrop, J., van Norren, K., and Clevers, H. (1992). A Gene Family of HMG-Box Transcription Factors with Homology to TCF-1. Nucl. Acids Res. 20, 611. doi:10.1093/nar/20.3.611

Cavallo, R. A., Cox, R. T., Moline, M. M., Roose, J., Polevoy, G. A., Clevers, H., et al. (1998). Drosophila Tcf and Groucho Interact to Repress Wingless Signalling Activity. Nature 395, 604-608. doi:10.1038/26982

Chambers, M., Turki-Judeh, W., Kim, M. W., Chen, K., Gallaher, S. D., and Courey, A. J. (2017). Mechanisms of Groucho-Mediated Repression Revealed by Genome-wide Analysis of Groucho Binding and Activity. BMC Genomics 18, 215. doi:10.1186/s12864-017-3589-6

Chanoumidou, K., Hadjimichael, C., Athanasouli, P., Ahlenius, H., Klonizakis, A., Nikolaou, C., et al. (2018). Groucho Related Gene 5 (GRG5) Is Involved in Embryonic and Neural Stem Cell State Decisions. Sci. Rep. 8, 13790. doi:10.1038/s41598-018-31696-9

Chellappa, R., Li, S., Pauley, S., Jahan, I., Jin, K., and Xiang, M. (2008). Barhl1 Regulatory Sequences Required for Cell-specific Gene Expression and Autoregulation in the Inner Ear and Central Nervous System. Mol. Cel Biol 28, 1905-1914. doi:10.1128/MCB.01454-07

Chen, C.-Y., Cheng, Y.-Y., Yen, C. Y. T., and Hsieh, P. C. H. (2017). Mechanisms of Pluripotency Maintenance in Mouse Embryonic Stem Cells. Cel. Mol. Life Sci. 74, 1805-1817. doi:10.1007/s00018-016-2438-0

Chen, G., Fernandez, J., Mische, S., and Courey, A. J. (1999). A Functional Interaction Between the Histone Deacetylase Rpd3 and the Corepressor Groucho in Drosophila Development. Genes Develop. 13, 2218-2230. doi:10.1101/gad.13.17.2218

Chiang, C., Litingtung, Y., Lee, E., Young, K. E., Corden, J. L., Westphal, H., et al. (1996). Cyclopia and Defective Axial Patterning in Mice Lacking Sonic Hedgehog Gene Function. Nature 383, 407-413. doi:10.1038/383407a0

Chodaparambil, J. V., Pate, K. T., Hepler, M. R. D., Tsai, B. P., Muthurajan, U. M., Luger, K., et al. (2014). Molecular Functions of the TLE Tetramerization Domain in Wnt Target Gene Repression. EMBO J. 33, 719-731. doi:10.1002/embj.201387188

Cinnamon, E., Helman, A., Ben-Haroush Schyr, R., Orian, A., Jime'nez, G., and Paroush, Z. e. (2008). Multiple RTK Pathways Downregulate GrouchoMediated Repression inDrosophilaembryogenesis. Development 135, 829-837. doi:10.1242/dev.015206

Cinnamon, E., and Paroush, Z. e. (2008). Context-dependent Regulation of Groucho/TLE-Mediated Repression. Curr. Opin. Genet. Develop. 18, 435-440. doi:10.1016/j.gde.2008.07.010

Cole, M. F., Johnstone, S. E., Newman, J. J., Kagey, M. H., and Young, R. A. (2008). Tcf3 Is an Integral Component of the Core Regulatory Circuitry of Embryonic Stem Cells. Genes Develop. 22, 746-755. doi:10.1101/gad.1642408

Colombo, A., Reig, G., Mione, M., and Concha, M. L. (2006). Zebrafish BarH-like Genes Define Discrete Neural Domains in the Early Embryo. Gene Expr. Patterns 6, 347-352. doi:10.1016/j.modgep.2005.09.011

Daniel, J. M., and Reynolds, A. B. (1999). The Catenin P120(ctn) Interacts with Kaiso, a Novel BTB/POZ Domain Zinc finger Transcription Factor. Mol. Cel Biol 19, 3614-3623. doi:10.1128/MCB.19.5.3614

Daniels, D. L., and Weis, W. I. (2005). Beta-catenin Directly Displaces Groucho/ TLE Repressors from Tcf/Lef in Wnt-Mediated Transcription Activation. Nat. Struct. Mol. Biol. 12, 364-371. doi:10.1038/nsmb912

Davidson, K. C., Adams, A. M., Goodson, J. M., McDonald, C. E., Potter, J. C., Berndt, J. D., et al. (2012). Wnt $/ \beta$-catenin Signaling Promotes Differentiation, Not Self-Renewal, of Human Embryonic Stem Cells and Is Repressed by Oct4. Proc. Natl. Acad. Sci. U S A. 109, 4485-4490. doi:10.1073/pnas.1118777109

de Jaime-Soguero, A., Abreu de Oliveira, W., and Lluis, F. (2018). The Pleiotropic Effects of the Canonical Wnt Pathway in Early Development and Pluripotency. Genes 9, 93. doi:10.3390/genes9020093

De Robertis, E. M., Larraín, J., Oelgeschläger, M., and Wessely, O. (2000). The Establishment of Spemann's Organizer and Patterning of the Vertebrate Embryo. Nat. Rev. Genet. 1, 171-181. doi:10.1038/35042039

Ding, Q., Balasubramanian, R., Zheng, D., Liang, G., and Gan, L. (2017). Barhl2 Determines the Early Patterning of the Diencephalon by Regulating Shh. Mol. Neurobiol. 54, 4414-4420. doi:10.1007/s12035-016-0001-5 
Ding, Q., Chen, H., Xie, X., Libby, R. T., Tian, N., and Gan, L. (2009). BARHL2 Differentially Regulates the Development of Retinal Amacrine and Ganglion Neurons. J. Neurosci. 29, 3992-4003. doi:10.1523/JNEUROSCI.5237-08.2009

Ding, Y., Colozza, G., Zhang, K., Moriyama, Y., Ploper, D., Sosa, E. A., et al. (2017). Genome-wide Analysis of Dorsal and Ventral Transcriptomes of the Xenopus laevis Gastrula. Dev. Biol. 426, 176-187. doi:10.1016/j.ydbio.2016.02.032

Doenz, G., Dorn, S., Aghaallaei, N., Bajoghli, B., Riegel, E., Aigner, M., et al. (2018). The Function of Tcf3 in Medaka Embryos: Efficient Knockdown with pePNAs. BMC Biotechnol. 18, 1. doi:10.1186/s12896-017-0411-0

Dorsky, R. I., Itoh, M., Moon, R. T., and Chitnis, A. (2003). Two Tcf3 Genes Cooperate to Pattern the Zebrafish Brain. Development 130, 1937-1947. doi:10.1242/dev.00402

Dorsky, R. I., Snyder, A., Cretekos, C. J., Grunwald, D. J., Geisler, R., Haffter, P., et al. (1999). Maternal and Embryonic Expression of Zebrafish Lef1. Mech. Dev. 86, 147-150. doi:10.1016/S0925-4773(99)00101-X

Doumpas, N., Lampart, F., Robinson, M. D., Lentini, A., Nestor, C. E., Cantù, C., et al. (2019). TCF/LEF Dependent and Independent Transcriptional Regulation of Wnt/ß-Catenin Target Genes. EMBO J. 38, e98873. doi:10.15252/ embj.201798873

Dubnicoff, T., Valentine, S. A., Chen, G., Shi, T., Lengyel, J. A., Paroush, Z., et al. (1997). Conversion of Dorsal from an Activator to a Repressor by the Global Corepressor Groucho. Genes Dev. 11, 2952-2957. doi:10.1101/gad.11.22.2952

Eshelman, M. A., Shah, M., Raup-Konsavage, W. M., Rennoll, S. A., and Yochum, G. S. (2017). TCF7L1 Recruits CtBP and HDAC1 to Repress DICKKOPF4 Gene Expression in Human Colorectal Cancer Cells. Biochem. Biophys. Res. Commun. 487, 716-722. doi:10.1016/j.bbrc.2017.04.123

Fan, M. J., Grüning, W., Walz, G., and Sokol, S. Y. (1998). Wnt Signaling and Transcriptional Control of Siamois in Xenopus Embryos. Proc. Natl. Acad. Sci. U S A. 95, 5626-5631. doi:10.1073/pnas.95.10.5626

Fang, L., Zhu, Q., Neuenschwander, M., Specker, E., Wulf-Goldenberg, A., Weis, W. I., et al. (2016). A Small-Molecule Antagonist of the $\beta$-Catenin/TCF4 Interaction Blocks the Self-Renewal of Cancer Stem Cells and Suppresses Tumorigenesis. Cancer Res. 76, 891-901. doi:10.1158/0008-5472.CAN-15-1519

Fang, M., Li, J., Blauwkamp, T., Bhambhani, C., Campbell, N., and Cadigan, K. M. (2006). C-terminal-binding Protein Directly Activates and Represses Wnt Transcriptional Targets in Drosophila. EMBO J. 25, 2735-2745. doi:10.1038/ sj.emboj.7601153

Fisher, A. L., Ohsako, S., and Caudy, M. (1996). The WRPW Motif of the HairyRelated Basic Helix-loop-helix Repressor Proteins Acts as a 4-Amino-Acid Transcription Repression and Protein-Protein Interaction Domain. Mol. Cel Biol 16, 2670-2677. doi:10.1128/MCB.16.6.2670

Flack, J. E., Mieszczanek, J., Novcic, N., and Bienz, M. (2017). Wnt-Dependent Inactivation of the Groucho/TLE Co-repressor by the HECT E3 Ubiquitin Ligase Hyd/UBR5. Mol. Cel 67, 181-193.e5. doi:10.1016/j.molcel.2017.06.009

Flores-Saaib, R. D., Jia, S., and Courey, A. J. (2001). Activation and Repression by the C-Terminal Domain of Dorsal. Development 128, 1869-1879. doi:10.1242/ dev.128.10.1869

Franz, A., Shlyueva, D., Brunner, E., Stark, A., and Basler, K. (2017). Probing the Canonicity of the Wnt/Wingless Signaling Pathway. Plos Genet. 13, e1006700. doi:10.1371/journal.pgen.1006700

Freeman, J., Smith, D., Latinkic, B., Ewan, K., Samuel, L., Zollo, M., et al. (2015). A Functional Connectome: Regulation of Wnt/TCF-dependent Transcription by Pairs of Pathway Activators. Mol. Cancer 14, 206. doi:10.1186/s12943-0150475-1

Friedmann-Morvinski, D., and Verma, I. M. (2014). Dedifferentiation and Reprogramming: Origins of Cancer Stem Cells. EMBO Rep. 15, 244-253. doi:10.1002/embr.201338254

Galceran, J., Miyashita-Lin, E. M., Devaney, E., Rubenstein, J. L., and Grosschedl, R. (2000). Hippocampus Development and Generation of Dentate Gyrus Granule Cells Is Regulated by LEF1. Development 127, 469-482. doi:10.1242/ dev.127.3.469

Garbe, D. S., and Ring, R. H. (2012). Investigating Tonic Wnt Signaling Throughout the Adult CNS and in the Hippocampal Neurogenic Niche of BatGal and Ins-TopGal Mice. Cell Mol Neurobiol 32, 1159-1174. doi:10.1007/ s10571-012-9841-3

Garcia-Lopez, J., Kumar, R., Smith, K. S., and Northcott, P. A. (2021). Deconstructing Sonic Hedgehog Medulloblastoma: Molecular Subtypes, Drivers, and beyond. Trends Genet. 37, 235-250. doi:10.1016/j.tig.2020.11.001
Gehring, W. J., Qian, Y. Q., Billeter, M., Furukubo-Tokunaga, K., Schier, A. F., Resendez-Perez, D., et al. (1994). Homeodomain-DNA Recognition. Cell 78, 211-223. doi:10.1016/0092-8674(94)90292-5

Gerner-Mauro, K. N., Akiyama, H., and Chen, J. (2020). Redundant and Additive Functions of the Four Lef/Tcf Transcription Factors in Lung Epithelial Progenitors. Proc. Natl. Acad. Sci. U S A. 117, 12182-12191. doi:10.1073/ pnas. 2002082117

Ghogomu, S. M., van Venrooy, S., Ritthaler, M., Wedlich, D., and Gradl, D. (2006). HIC-5 Is a Novel Repressor of Lymphoid Enhancer factor/T-Cell Factor-Driven Transcription. J. Biol. Chem. 281, 1755-1764. doi:10.1074/jbc.M505869200

Glinka, A., Wu, W., Delius, H., Monaghan, A. P., Blumenstock, C., and Niehrs, C. (1998). Dickkopf-1 Is a Member of a New Family of Secreted Proteins and Functions in Head Induction. Nature 391, 357-362. doi:10.1038/34848

Gradl, D., König, A., and Wedlich, D. (2002). Functional Diversity of Xenopus Lymphoid Enhancer Factor/T-Cell Factor Transcription Factors Relies on Combinations of Activating and Repressing Elements. J. Biol. Chem. 277, 14159-14171. doi:10.1074/jbc.M107055200

Graham, T. A., Weaver, C., Mao, F., Kimelman, D., and Xu, W. (2000). Crystal Structure of a Beta-catenin/Tcf Complex. Cell 103, 885-896. doi:10.1016/s00928674(00)00192-6

Grbavec, D., Lo, R., Liu, Y., and Stifani, S. (1998). Transducin-like Enhancer of Split 2, a Mammalian Homologue of Drosophila Groucho, Acts as a Transcriptional Repressor, Interacts with Hairy/Enhancer of Split Proteins, and Is Expressed During Neuronal Development. Eur. J. Biochem. 258, 339-349. doi:10.1046/ j.1432-1327.1998.2580339.x

Hanson, A. J., Wallace, H. A., Freeman, T. J., Beauchamp, R. D., Lee, L. A., and Lee, E. (2012). XIAP Monoubiquitylates Groucho/TLE to Promote Canonical Wnt Signaling. Mol. Cel 45, 619-628. doi:10.1016/j.molcel.2011.12.032

Hao, J., Li, T. G., Qi, X., Zhao, D. F., and Zhao, G. Q. (2006). WNT/beta-catenin Pathway Up-Regulates Stat3 and Converges on LIF to Prevent Differentiation of Mouse Embryonic Stem Cells. Dev. Biol. 290, 81-91. doi:10.1016/ j.ydbio.2005.11.011

Hashimoto-Torii, K., Motoyama, J., Hui, C. C., Kuroiwa, A., Nakafuku, M., and Shimamura, K. (2003). Differential Activities of Sonic Hedgehog Mediated by Gli Transcription Factors Define Distinct Neuronal Subtypes in the Dorsal Thalamus. Mech. Dev. 120, 1097-1111. doi:10.1016/j.mod.2003.09.001

Hatten, M. E., and Roussel, M. F. (2011). Development and Cancer of the Cerebellum. Trends Neurosci. 34, 134-142. doi:10.1016/j.tins.2011.01.002

He, T. C., Sparks, A. B., Rago, C., Hermeking, H., Zawel, L., da Costa, L. T., et al. (1998). Identification of C-MYC as a Target of the APC Pathway. Science 281, 1509-1512. doi:10.1126/science.281.5382.1509

Heimbucher, T., Murko, C., Bajoghli, B., Aghaallaei, N., Huber, A., Stebegg, R., et al. (2007). Gbx2 and Otx2 Interact with the WD40 Domain of Groucho/Tle Corepressors. Mol. Cel Biol 27, 340-351. doi:10.1128/MCB.00811-06

Heisenberg, C. P., Houart, C., Take-Uchi, M., Rauch, G. J., Young, N., Coutinho, P., et al. (2001). A Mutation in the Gsk3-Binding Domain of Zebrafish Masterblind/Axin1 Leads to a Fate Transformation of Telencephalon and Eyes to Diencephalon. Genes Dev. 15, 1427-1434. doi:10.1101/gad.194301

Higashijima, S., Kojima, T., Michiue, T., Ishimaru, S., Emori, Y., and Saigo, K. (1992). Dual Bar Homeo Box Genes of Drosophila Required in Two Photoreceptor Cells, R1 and R6, and Primary Pigment Cells for Normal Eye Development. Genes Dev. 6, 50-60. doi:10.1101/gad.6.1.50

Hikasa, H., Ezan, J., Itoh, K., Li, X., Klymkowsky, M. W., and Sokol, S. Y. (2010). Regulation of TCF3 by Wnt-dependent Phosphorylation During Vertebrate Axis Specification. Dev. Cel 19, 521-532. doi:10.1016/ j.devcel.2010.09.005

Hikasa, H., and Sokol, S. Y. (2011). Phosphorylation of TCF Proteins by Homeodomain-Interacting Protein Kinase 2. J. Biol. Chem. 286, 12093-12100. doi:10.1074/jbc.M110.185280

Hoch, R. V., Rubenstein, J. L., and Pleasure, S. (2009). Genes and Signaling Events that Establish Regional Patterning of the Mammalian Forebrain. Semin. Cel Dev Biol 20, 378-386. doi:10.1016/j.semcdb.2009.02.005

Hoffmeyer, K., Raggioli, A., Rudloff, S., Anton, R., Hierholzer, A., Del Valle, I., et al. (2012). Wnt/ $\beta$-catenin Signaling Regulates Telomerase in Stem Cells and Cancer Cells. Science 336, 1549-1554. doi:10.1126/science.1218370

Hoppler, S., and Waterman, M. L. (2014). "Evolutionary Diversification of Vertebrate TCF/LEF Structure, Function, and Regulation," in Wht Signaling 
In Development And Disease. Editors S. Hoppler and R. T. Moon (Hoboken, NJ: John Wiley \& Sons), 225-237. doi:10.1002/9781118444122.ch17

Horst, D., Chen, J., Morikawa, T., Ogino, S., Kirchner, T., and Shivdasani, R. A. (2012). Differential WNT Activity in Colorectal Cancer Confers Limited Tumorigenic Potential and Is Regulated by MAPK Signaling. Cancer Res. 72, 1547-1556. doi:10.1158/0008-5472.CAN-11-3222

Houston, D. W., Kofron, M., Resnik, E., Langland, R., Destree, O., Wylie, C., et al. (2002). Repression of Organizer Genes in Dorsal and Ventral Xenopus Cells Mediated by Maternal XTcf3. Development 129, 4015-4025. doi:10.1242/ dev.129.17.4015

Hovanes, K., Li, T. W. H., Munguia, J. E., Truong, T., Milovanovic, T., Lawrence Marsh, J., et al. (2001). $\beta$-catenin-sensitive Isoforms of Lymphoid Enhancer Factor-1 Are Selectively Expressed in colon Cancer. Nat. Genet. 28, 53-57. doi:10.1038/ng0501-53

Hovestadt, V., Ayrault, O., Swartling, F. J., Robinson, G. W., Pfister, S. M., and Northcott, P. A. (2020). Medulloblastomics Revisited: Biological and Clinical Insights from Thousands of Patients. Nat. Rev. Cancer 20, 42-56. doi:10.1038/ s41568-019-0223-8

Ishibashi, M., and McMahon, A. P. (2002). A Sonic Hedgehog-dependent Signaling Relay Regulates Growth of Diencephalic and Mesencephalic Primordia in the Early Mouse Embryo. Development 129, 4807-4819.

Isobe, T., Hisamori, S., Hogan, D. J., Zabala, M., Hendrickson, D. G., Dalerba, P., et al. (2014). miR-142 Regulates the Tumorigenicity of Human Breast Cancer Stem Cells Through the Canonical WNT Signaling Pathway. Elife 3, e01977. doi:10.7554/eLife.01977

Jennings, B. H., and Ish-Horowicz, D. (2008). The Groucho/TLE/Grg Family of Transcriptional Co-repressors. Genome Biol. 9, 205. doi:10.1186/gb-2008-91-205

Jennings, B. H., Pickles, L. M., Wainwright, S. M., Roe, S. M., Pearl, L. H., and IshHorowicz, D. (2006). Molecular Recognition of Transcriptional Repressor Motifs by the WD Domain of the Groucho/TLE Corepressor. Mol. Cel 22, 645-655. doi:10.1016/j.molcel.2006.04.024

Jiménez, G., Paroush, Z., and Ish-Horowicz, D. (1997). Groucho Acts as a Corepressor for a Subset of Negative Regulators, Including Hairy and Engrailed. Genes Dev. 11, 3072-3082. doi:10.1101/gad.11.22.3072

Jones, E. G., and Rubenstein, J. L. (2004). Expression of Regulatory Genes During Differentiation of Thalamic Nuclei in Mouse and Monkey. J. Comp. Neurol. 477, 55-80. doi:10.1002/cne.20234

Jung, Y. S., and Park, J. I. (2020). Wnt Signaling in Cancer: Therapeutic Targeting of Wnt Signaling beyond $\beta$-catenin and the Destruction Complex. Exp. Mol. Med. 52, 183-191. doi:10.1038/s12276-020-0380-6

Juraver-Geslin, H. A., Ausseil, J. J., Wassef, M., and Durand, B. C. (2011). Barhl2 Limits Growth of the Diencephalic Primordium Through Caspase3 Inhibition of Beta-Catenin Activation. Proc. Natl. Acad. Sci. U S A. 108, 2288-2293. doi:10.1073/pnas.1014017108

Juraver-Geslin, H. A., and Durand, B. C. (2015). Early Development of the Neural Plate: New Roles for Apoptosis and for One of its Main Effectors Caspase-3. Genesis 53, 203-224. doi:10.1002/dvg.22844

Juraver-Geslin, H. A., Gómez-Skarmeta, J. L., and Durand, B. C. (2014). The Conserved barH-like Homeobox-2 Gene Barhl2 Acts Downstream of Orthodentricle-2 and Together with iroquois-3 in Establishment of the Caudal Forebrain Signaling center Induced by Sonic Hedgehog. Dev. Biol. 396, 107-120. doi:10.1016/j.ydbio.2014.09.027

Jusuf, P. R., Albadri, S., Paolini, A., Currie, P. D., Argenton, F., Higashijima, S., et al. (2012). Biasing Amacrine Subtypes in the Atoh7 Lineage Through Expression of Barhl2. J. Neurosci. 32, 13929-13944. doi:10.1523/JNEUROSCI.207312.2012

Kalani, M. Y., Cheshier, S. H., Cord, B. J., Bababeygy, S. R., Vogel, H., Weissman, I. L., et al. (2008). Wnt-mediated Self-Renewal of Neural Stem/progenitor Cells. Proc. Natl. Acad. Sci. U S A. 105, 16970-16975. doi:10.1073/pnas.0808616105

Kaul, A., Schuster, E., and Jennings, B. H. (2014). The Groucho Co-repressor Is Primarily Recruited to Local Target Sites in Active Chromatin to Attenuate Transcription. Plos Genet. 10, e1004595. doi:10.1371/ journal.pgen.1004595

Kawauchi, D., and Saito, T. (2008). Transcriptional Cascade from Math1 to Mbh1 and Mbh2 Is Required for Cerebellar Granule Cell Differentiation. Dev. Biol. 322, 345-354. doi:10.1016/j.ydbio.2008.08.005
Kiecker, C., and Lumsden, A. (2012). The Role of Organizers in Patterning the Nervous System. Annu. Rev. Neurosci. 35, 347-367. doi:10.1146/annurevneuro-062111-150543

Kim, C. H., Oda, T., Itoh, M., Jiang, D., Artinger, K. B., Chandrasekharappa, S. C., et al. (2000). Repressor Activity of Headless/Tcf3 Is Essential for Vertebrate Head Formation. Nature 407, 913-916. doi:10.1038/35038097

Kim, J. Y., Lee, J. S., Hwang, H. S., Lee, D. R., Park, C. Y., Jung, S. J., et al. (2018). Wnt Signal Activation Induces Midbrain Specification Through Direct Binding of the Beta-catenin/TCF4 Complex to the EN1 Promoter in Human Pluripotent Stem Cells. Exp. Mol. Med. 50, 24-13. doi:10.1038/s12276-018-0044-y

King, N., Westbrook, M. J., Young, S. L., Kuo, A., Abedin, M., Chapman, J., et al. (2008). The Genome of the Choanoflagellate Monosiga Brevicollis and the Origin of Metazoans. Nature 451, 783-788. doi:10.1038/nature06617

Kojima, T., Ishimaru, S., Higashijima, S., Takayama, E., Akimaru, H., Sone, M., et al. (1991). Identification of a Different-type Homeobox Gene, BarH1, Possibly Causing Bar (B) and Om(1D) Mutations in Drosophila. Proc. Natl. Acad. Sci. U S A. 88, 4343-4347. doi:10.1073/pnas.88.10.4343

Korinek, V., Barker, N., Willert, K., Molenaar, M., Roose, J., Wagenaar, G., et al. (1998). Two Members of the Tcf Family Implicated in Wnt/beta-Catenin Signaling During Embryogenesis in the Mouse. Mol. Cel Biol 18, 1248-1256. doi:10.1128/MCB.18.3.1248

Kormish, J. D., Sinner, D., and Zorn, A. M. (2009). Interactions Between SOX Factors and Wnt/ $\beta$-Catenin Signaling in Development and Disease. Dev. Dyn. 239, 56-68. doi:10.1002/dvdy.22046

Kratochwil, K., Galceran, J., Tontsch, S., Roth, W., and Grosschedl, R. (2002). FGF4, a Direct Target of LEF1 and Wnt Signaling, Can Rescue the Arrest of Tooth Organogenesis in Lef1(-/-) Mice. Genes Dev. 16, 3173-3185. doi:10.1101/ gad. 1035602

Kraus, Y., Aman, A., Technau, U., and Genikhovich, G. (2016). Pre-bilaterian Origin of the Blastoporal Axial Organizer. Nat. Commun. 7, 11694. doi:10.1038/ ncomms 11694

Kuwabara, T., Hsieh, J., Muotri, A., Yeo, G., Warashina, M., Lie, D. C., et al. (2009). Wnt-mediated Activation of NeuroD1 and Retro-Elements During Adult Neurogenesis. Nat. Neurosci. 12, 1097-1105. doi:10.1038/nn.2360

Kuwahara, A., Sakai, H., Xu, Y., Itoh, Y., Hirabayashi, Y., and Gotoh, Y. (2014). Tcf3 Represses Wnt- $\beta$-Catenin Signaling and Maintains Neural Stem Cell Population During Neocortical Development. PLoS One 9, e94408. doi:10.1371/journal.pone.0094408

Laing, A. F., Lowell, S., and Brickman, J. M. (2015). Gro/TLE Enables Embryonic Stem Cell Differentiation by Repressing Pluripotent Gene Expression. Dev. Biol. 397, 56-66. doi:10.1016/j.ydbio.2014.10.007

Larabell, C. A., Torres, M., Rowning, B. A., Yost, C., Miller, J. R., Wu, M., et al. (1997). Establishment of the Dorso-Ventral axis in Xenopus Embryos Is Presaged by Early Asymmetries in Beta-Catenin that Are Modulated by the Wnt Signaling Pathway. J. Cel Biol 136, 1123-1136. doi:10.1083/ jcb.136.5.1123

Larsen, C. W., Zeltser, L. M., and Lumsden, A. (2001). Boundary Formation and Compartition in the Avian Diencephalon. J. Neurosci. 21, 4699-4711. doi:10.1523/JNEUROSCI.21-13-04699.2001

Laurent, M. N., Blitz, I. L., Hashimoto, C., Rothbächer, U., and Cho, K. W. (1997). The Xenopus Homeobox Gene Twin Mediates Wnt Induction of Goosecoid in Establishment of Spemann's Organizer. Development 124, 4905-4916. doi:10.1242/dev.124.23.4905

Lee, S. M., Tole, S., Grove, E., and McMahon, A. P. (2000). A Local Wnt-3a Signal Is Required for Development of the Mammalian hippocampus. Development 127, 457-467. doi:10.1242/dev.127.3.457

Lee, T. I., Jenner, R. G., Boyer, L. A., Guenther, M. G., Levine, S. S., Kumar, R. M., et al. (2006). Control of Developmental Regulators by Polycomb in Human Embryonic Stem Cells. Cell 125, 301-313. doi:10.1016/j.cell.2006.02.043

Lemaire, P., Garrett, N., and Gurdon, J. B. (1995). Expression Cloning of Siamois, a Xenopus Homeobox Gene Expressed in Dorsal-Vegetal Cells of Blastulae and Able to Induce a Complete Secondary Axis. Cell 81, 85-94. doi:10.1016/00928674(95) $90373-9$

Lemoine, F., Correia, D., Lefort, V., Doppelt-Azeroual, O., Mareuil, F., CohenBoulakia, S., et al. (2019). NGPhylogeny.fr: New Generation Phylogenetic Services for Non-specialists. Nucleic Acids Res. 47, W260-W265. doi:10.1093/nar/gkz303 
Leto, K., Arancillo, M., Becker, E. B., Buffo, A., Chiang, C., Ding, B., et al. (2016). Consensus Paper: Cerebellar Development. Cerebellum 15, 789-828. doi:10.1007/s12311-015-0724-2

Lien, W. H., Polak, L., Lin, M., Lay, K., Zheng, D., and Fuchs, E. (2014). In vivo Transcriptional Governance of Hair Follicle Stem Cells by Canonical Wnt Regulators. Nat. Cel Biol 16, 179-190. doi:10.1038/ncb2903

Lin, C. Y., Erkek, S., Tong, Y., Yin, L., Federation, A. J., Zapatka, M., et al. (2016). Active Medulloblastoma Enhancers Reveal Subgroup-specific Cellular Origins. Nature 530, 57-62. doi:10.1038/nature16546

Lin, R., Thompson, S., and Priess, J. R. (1995). pop-1 Encodes an HMG Box Protein Required for the Specification of a Mesoderm Precursor in Early C. elegans Embryos. Cell 83, 599-609. doi:10.1016/0092-8674(95)90100-0

Liston, P., Fong, W. G., and Korneluk, R. G. (2003). The Inhibitors of Apoptosis: There Is More to Life Than Bcl2. Oncogene 22, 8568-8580. doi:10.1038/ si.onc. 1207101

Liu, F., van den Broek, O., Destrée, O., and Hoppler, S. (2005). Distinct Roles for Xenopus Tcf/Lef Genes in Mediating Specific Responses to Wnt/beta-Catenin Signalling in Mesoderm Development. Development 132, 5375-5385. doi:10.1242/dev.02152

Louvi, A., Yoshida, M., and Grove, E. A. (2007). The Derivatives of the Wnt3a Lineage in the Central Nervous System. J. Comp. Neurol. 504, 550-569. doi:10.1002/cne.21461

Lowe, C. J., Wu, M., Salic, A., Evans, L., Lander, E., Stange-Thomann, N., et al. (2003). Anteroposterior Patterning in Hemichordates and the Origins of the Chordate Nervous System. Cell 113, 853-865. doi:10.1016/S0092-8674(03) 00469-0

MacDonald, B. T., Tamai, K., and He, X. (2009). Wnt/beta-catenin Signaling: Components, Mechanisms, and Diseases. Dev. Cel 17, 9-26. doi:10.1016/ j.devcel.2009.06.016

Malarkey, C. S., and Churchill, M. E. (2012). The High Mobility Group Box: The Ultimate Utility Player of a Cell. Trends Biochem. Sci. 37, 553-562. doi:10.1016/ j.tibs.2012.09.003

Marson, A., Levine, S. S., Cole, M. F., Frampton, G. M., Brambrink, T., Johnstone, S., et al. (2008). Connecting microRNA Genes to the Core Transcriptional Regulatory Circuitry of Embryonic Stem Cells. Cell 134, 521-533. doi:10.1016/ j.cell.2008.07.020

Martínez, S., and Puelles, L. (2000). "Neurogenetic Compartments of the Mouse Diencephalon and Some Characteristic Gene Expression Patterns," in Mouse Brain Development Results and Problems in Cell Differentiation. Editors A. M. Goffinet and P. Rakic (Berlin, Heidelberg: Springer Berlin Heidelberg), 91-106. doi:10.1007/978-3-540-48002-0_4

Mattes, B., Weber, S., Peres, J., Chen, Q., Davidson, G., Houart, C., et al. (2012). Wnt3 and Wnt3a Are Required for Induction of the Mid-diencephalic Organizer in the Caudal Forebrain. Neural Dev. 7, 12. doi:10.1186/17498104-7-12

McCrea, P. D., Brieher, W. M., and Gumbiner, B. M. (1993). Induction of a Secondary Body axis in Xenopus by Antibodies to Beta-Catenin. J. Cel Biol 123, 477-484. doi:10.1083/jcb.123.2.477

McMahon, A. P., and Moon, R. T. (1989). Ectopic Expression of the ProtoOncogene Int-1 in Xenopus Embryos Leads to Duplication of the Embryonic axis. Cell 58, 1075-1084. doi:10.1016/0092-8674(89)90506-0

Megason, S. G., and McMahon, A. P. (2002). A Mitogen Gradient of Dorsal Midline Wnts Organizes Growth in the CNS. Development 129, 2087-2098. doi:10.1242/dev.129.9.2087

Merrill, B. J., Pasolli, H. A., Polak, L., Rendl, M., García-García, M. J., Anderson, K. V., et al. (2004). Tcf3: A Transcriptional Regulator of axis Induction in the Early Embryo. Development 131, 263-274. doi:10.1242/dev.00935

Merrill, B. J. (2012). Wnt Pathway Regulation of Embryonic Stem Cell SelfRenewal. Cold Spring Harbor Perspect. Biol. 4, a007971. doi:10.1101/ cshperspect.a007971

Mo, Z., Li, S., Yang, X., and Xiang, M. (2004). Role of the Barhl2 Homeobox Gene in the Specification of Glycinergic Amacrine Cells. Development 131, 1607-1618. doi:10.1242/dev.01071

Molenaar, M., Roose, J., Peterson, J., Venanzi, S., Clevers, H., and Destrée, O. (1998). Differential Expression of the HMG Box Transcription Factors XTcf-3 and XLef-1 During Early Xenopus Development. Mech. Dev. 75, 151-154. doi:10.1016/S0925-4773(98)00085-9
Molenaar, M., van de Wetering, M., Oosterwegel, M., Peterson-Maduro, J., Godsave, S., Korinek, V., et al. (1996). XTcf-3 Transcription Factor Mediates Beta-Catenin-Induced Axis Formation in Xenopus Embryos. Cell 86, 391-399. doi:10.1016/S0092-8674(00)80112-9

Moreira, S., Polena, E., Gordon, V., Abdulla, S., Mahendram, S., Cao, J., et al. (2017). A Single TCF Transcription Factor, Regardless of its Activation Capacity, Is Sufficient for Effective Trilineage Differentiation of ESCs. Cell Rep 20, 2424-2438. doi:10.1016/j.celrep.2017.08.043

Muhr, J., Andersson, E., Persson, M., Jessell, T. M., and Ericson, J. (2001). Grouchomediated Transcriptional Repression Establishes Progenitor Cell Pattern and Neuronal Fate in the Ventral Neural Tube. Cell 104, 861-873. doi:10.1016/ S0092-8674(01)00283-5

Mukherjee, S., Luedeke, D. M., Brown, L., and Zorn, A. M. (2021). SOX Transcription Factors Direct TCF-independent WNT/beta-catenin Transcription. bioRxiv doi:10.1101/2021.08.25.457694

Muncan, V., Faro, A., Haramis, A. P., Hurlstone, A. F., Wienholds, E., van Es, J., et al. (2007). T-cell Factor 4 (Tcf7l2) Maintains Proliferative Compartments in Zebrafish Intestine. EMBO Rep. 8, 966-973. doi:10.1038/sj.embor.7401071

Nakamura, Y., and Hoppler, S. (2017). Genome-wide Analysis of Canonical Wnt Target Gene Regulation in Xenopus Tropicalis Challenges $\beta$-catenin Paradigm. Genesis 55, e22991. doi:10.1002/dvg.22991

Nakamura, Y., de Paiva Alves, E., Veenstra, G. J., and Hoppler, S. (2016). Tissueand Stage-specific Wnt Target Gene Expression Is Controlled Subsequent to $\beta$-catenin Recruitment. Development 143, 1914-1925. doi:10.1242/dev.131664

Nehme, R., Grote, P., Tomasi, T., Löser, S., Holzkamp, H., Schnabel, R., et al. (2010). Transcriptional Upregulation of Both Egl-1 BH3-Only and Ced-3 Caspase Is Required for the Death of the Male-specific CEM Neurons. Cell Death Differ 17, 1266-1276. doi:10.1038/cdd.2010.3

Ng, L. F., Kaur, P., Bunnag, N., Suresh, J., Sung, I. C. H., Tan, Q. H., et al. (2019). WNT Signaling in Disease. Cells 8, 826. doi:10.3390/cells8080826

Niehrs, C. (2004). Regionally Specific Induction by the Spemann-Mangold Organizer. Nat. Rev. Genet. 5, 425-434. doi:10.1038/nrg1347

Niehrs, C. (2012). The Complex World of WNT Receptor Signalling. Nat. Rev. Mol. Cel Biol 13, 767-779. doi:10.1038/nrm3470

Niwa, H. (2011). Wnt: What's Needed to Maintain Pluripotency? Nat. Cel Biol 13, 1024-1026. doi:10.1038/ncb2333

Noelanders, R., and Vleminckx, K. (2017). How Wnt Signaling Builds the Brain: Bridging Development and Disease. Neuroscientist 23, 314-329. doi:10.1177/ 1073858416667270

Noureen, N., Wu, S., Lv, Y., Yang, J., Alfred Yung, W. K., Gelfond, J., et al. (2021). Integrated Analysis of Telomerase Enzymatic Activity Unravels an Association with Cancer Stemness and Proliferation. Nat. Commun. 12, 139. doi:10.1038/ s41467-020-20474-9

Nusse, R., and Clevers, H. (2017). Wnt/ $\beta$-Catenin Signaling, Disease, and Emerging Therapeutic Modalities. Cell 169, 985-999. doi:10.1016/j.cell.2017.05.016

Nusse, R., and Varmus, H. (2012). Three Decades of Wnts: A Personal Perspective on How a Scientific Field Developed. EMBO J. 31, 2670-2684. doi:10.1038/ emboj.2012.146

Nusse, R., and Varmus, H. E. (1982). Many Tumors Induced by the Mouse Mammary Tumor Virus Contain a Provirus Integrated in the Same Region of the Host Genome. Cell 31, 99-109. doi:10.1016/0092-8674(82)90409-3

Oberst, P., Fièvre, S., Baumann, N., Concetti, C., Bartolini, G., and Jabaudon, D. (2019). Temporal Plasticity of Apical Progenitors in the Developing Mouse Neocortex. Nature 573, 370-374. doi:10.1038/s41586-019-1515-6

Offner, N., Duval, N., Jamrich, M., and Durand, B. (2005). The Pro-apoptotic Activity of a Vertebrate Bar-like Homeobox Gene Plays a Key Role in Patterning the Xenopus Neural Plate by Limiting the Number of Chordinand Shh-Expressing Cells. Development 132, 1807-1818. doi:10.1242/ dev.01712

Ohtsuka, T., Shimojo, H., Matsunaga, M., Watanabe, N., Kometani, K., Minato, N., et al. (2011). Gene Expression Profiling of Neural Stem Cells and Identification of Regulators of Neural Differentiation During Cortical Development. Stem Cells 29, 1817-1828. doi:10.1002/stem.731

Owens, N. D. L., Blitz, I. L., Lane, M. A., Patrushev, I., Overton, J. D., Gilchrist, M. J., et al. (2016). Measuring Absolute RNA Copy Numbers at High Temporal Resolution Reveals Transcriptome Kinetics in Development. Cel Rep 14, 632-647. doi:10.1016/j.celrep.2015.12.050 
Ozair, M. Z., Kintner, C., and Brivanlou, A. H. (2013). Neural Induction and Early Patterning in Vertebrates. Wiley Interdiscip. Rev. Dev. Biol. 2, 479-498. doi:10.1002/wdev.90

Panhuysen, M., Vogt Weisenhorn, D. M., Blanquet, V., Brodski, C., Heinzmann, U., Beisker, W., et al. (2004). Effects of Wnt1 Signaling on Proliferation in the Developing Mid-/hindbrain Region. Mol. Cel Neurosci. 26, 101-111. doi:10.1016/j.mcn.2004.01.011

Pani, A. M., Mullarkey, E. E., Aronowicz, J., Assimacopoulos, S., Grove, E. A., and Lowe, C. J. (2012). Ancient Deuterostome Origins of Vertebrate Brain Signalling Centres. Nature 483, 289-294. doi:10.1038/nature10838

Park, J. I., Kim, S. W., Lyons, J. P., Ji, H., Nguyen, T. T., Cho, K., et al. (2005). Kaiso/ p120-catenin and TCF/beta-catenin Complexes Coordinately Regulate Canonical Wnt Gene Targets. Dev. Cel 8, 843-854. doi:10.1016/ j.devcel.2005.04.010

Park, J. I., Venteicher, A. S., Hong, J. Y., Choi, J., Jun, S., Shkreli, M., et al. (2009). Telomerase Modulates Wnt Signalling by Association with Target Gene Chromatin. Nature 460, 66-72. doi:10.1038/nature08137

Park, M. S., Kausar, R., Kim, M. W., Cho, S. Y., Lee, Y. S., and Lee, M. A. (2015). Tcf7l1-mediated Transcriptional Regulation of Krüppel-like Factor 4 Gene. Anim. Cell Syst. 19, 16-29. doi:10.1080/19768354.2014.991351

Parker, D. S., Jemison, J., and Cadigan, K. M. (2002). Pygopus, A Nuclear PHDfinger Protein Required for Wingless Signaling in Drosophila. Development 129, 2565-2576. doi:10.1242/dev.129.11.2565

Paroush, Z., Finley, R. L., Kidd, T., Wainwright, S. M., Ingham, P. W., Brent, R., et al. (1994). Groucho Is Required for Drosophila Neurogenesis, Segmentation, and Sex Determination and Interacts Directly with Hairy-Related bHLH Proteins. Cell 79, 805-815. doi:10.1016/0092-8674(94)90070-1

Patterson, K. D., Cleaver, O., Gerber, W. V., White, F. G., and Krieg, P. A. (2000). Distinct Expression Patterns for Two Xenopus Bar Homeobox Genes. Dev. Genes Evol. 210, 140-144. doi:10.1007/s004270050020

Peden, E., Kimberly, E., Gengyo-Ando, K., Mitani, S., and Xue, D. (2007). Control of Sex-specific Apoptosis in C. elegans by the BarH Homeodomain Protein CEH-30 and the Transcriptional Repressor UNC-37/Groucho. Genes Dev. 21, 3195-3207. doi:10.1101/gad.1607807

Pereira, L., Yi, F., and Merrill, B. J. (2006). Repression of Nanog Gene Transcription by Tcf3 Limits Embryonic Stem Cell Self-Renewal. Mol. Cel Biol 26, 7479-7491. doi:10.1128/MCB.00368-06

Pöschl, J., Lorenz, A., Hartmann, W., von Bueren, A. O., Kool, M., Li, S., et al. (2011). Expression of BARHL1 in Medulloblastoma Is Associated with Prolonged Survival in Mice and Humans. Oncogene 30, 4721-4730. doi:10.1038/onc.2011.173

Pukrop, T., Gradl, D., Henningfeld, K. A., Knochel, W., Wedlich, D., and Kuhl, M. (2001). Identification of Two Regulatory Elements Within the High Mobility Group Box Transcription Factor XTCF-4. J. Biol. Chem. 276, 8968-8978. doi:10.1074/jbc.M007533200

Quinlan, R., Graf, M., Mason, I., Lumsden, A., and Kiecker, C. (2009). Complex and Dynamic Patterns of Wnt Pathway Gene Expression in the Developing Chick Forebrain. Neural Dev. 4, 35. doi:10.1186/1749-8104-4-35

Ramakrishnan, A. B., Sinha, A., Fan, V. B., and Cadigan, K. M. (2018). The Wnt Transcriptional Switch: TLE Removal or Inactivation? Bioessays 40, 1700162. doi:10.1002/bies.201700162

Ravindranath, A., and Cadigan, K. M. (2014). Structure-Function Analysis of the C-Clamp of TCF/Pangolin in Wnt/B-Catenin Signaling. PLoS ONE 9, e86180. doi:10.1371/journal.pone.0086180

Reig, G., Cabrejos, M. E., and Concha, M. L. (2007). Functions of BarH Transcription Factors During Embryonic Development. Dev. Biol. 302, 367-375. doi:10.1016/j.ydbio.2006.10.008

Rocheleau, C. E., Downs, W. D., Lin, R., Wittmann, C., Bei, Y., Cha, Y. H., et al. (1997). Wnt Signaling and an APC-Related Gene Specify Endoderm in Early C. elegans Embryos. Cell 90, 707-716. doi:10.1016/S0092-8674(00)80531-0

Rodriguez-Blanco, J., Pednekar, L., Penas, C., Li, B., Martin, V., Long, J., et al. (2017). Inhibition of WNT Signaling Attenuates Self-Renewal of SHHSubgroup Medulloblastoma. Oncogene 36, 6306-6314. doi:10.1038/ onc.2017.232

Roël, G., Hamilton, F. S., Gent, Y., Bain, A. A., Destrée, O., and Hoppler, S. (2002). Lef- 1 and Tcf-3 Transcription Factors Mediate Tissue-specific Wnt Signaling During Xenopus Development. Curr. Biol. 12, 1941-1945. doi:10.1016/S09609822(02)01280-0
Roose, J., Molenaar, M., Peterson, J., Hurenkamp, J., Brantjes, H., Moerer, P., et al. (1998). The Xenopus Wnt Effector XTcf-3 Interacts with Groucho-Related Transcriptional Repressors. Nature 395, 608-612. doi:10.1038/26989

Rosenbloom, A. B., Tarczyński, M., Lam, N., Kane, R. S., Bugaj, L. J., and Schaffer, D. V. (2020). $\beta$-Catenin Signaling Dynamics Regulate Cell Fate in Differentiating Neural Stem Cells. Proc. Natl. Acad. Sci. U S A. 117, 28828-28837. doi:10.1073/pnas.2008509117

Röttinger, E., and Lowe, C. J. (2012). Evolutionary Crossroads in Developmental Biology: Hemichordates. Development 139, 2463-2475. doi:10.1242/dev.066712

Ruzov, A., Hackett, J. A., Prokhortchouk, A., Reddington, J. P., Madej, M. J., Dunican, D. S., et al. (2009). The Interaction of xKaiso with xTcf3: A Revised Model for Integration of Epigenetic and Wnt Signalling Pathways. Development 136, 723-727. doi:10.1242/dev.025577

Salomonis, N., Schlieve, C. R., Pereira, L., Wahlquist, C., Colas, A., Zambon, A. C., et al. (2010). Alternative Splicing Regulates Mouse Embryonic Stem Cell Pluripotency and Differentiation. Proc. Natl. Acad. Sci. U S A. 107, 10514-10519. doi:10.1073/pnas.0912260107

Sato, M., Kojima, T., Michiue, T., and Saigo, K. (1999). Bar Homeobox Genes Are Latitudinal Prepattern Genes in the Developing Drosophila Notum Whose Expression Is Regulated by the Concerted Functions of Decapentaplegic and Wingless. Development 126, 1457-1466. doi:10.1242/dev.126.7.1457

Schneider, S., Steinbeisser, H., Warga, R. M., and Hausen, P. (1996). Beta-catenin Translocation into Nuclei Demarcates the Dorsalizing Centers in Frog and Fish Embryos. Mech. Dev. 57, 191-198. doi:10.1016/0925-4773(96)00546-1

Scholpp, S., Foucher, I., Staudt, N., Peukert, D., Lumsden, A., and Houart, C. (2007). Otx1l, Otx2 and Irx1b Establish and Position the ZLI in the Diencephalon. Development 134, 3167-3176. doi:10.1242/dev.001461

Scholpp, S., Wolf, O., Brand, M., and Lumsden, A. (2006). Hedgehog Signalling from the Zona Limitans Intrathalamica Orchestrates Patterning of the Zebrafish Diencephalon. Development 133, 855-864. doi: $10.1242 /$ dev. 02248

Schuhmacher, L. N., Albadri, S., Ramialison, M., and Poggi, L. (2011). Evolutionary Relationships and Diversification of Barhl Genes within Retinal Cell Lineages. BMC Evol. Biol. 11, 340. doi:10.1186/1471-2148-11-340

Schuijers, J., Mokry, M., Hatzis, P., Cuppen, E., and Clevers, H. (2014). Wntinduced Transcriptional Activation Is Exclusively Mediated by TCF/LEF. EMBO J. 33, 146-156. doi:10.1002/embj.201385358

Schwartz, H. T., and Horvitz, H. R. (2007). The C. elegans Protein CEH-30 Protects Male-specific Neurons from Apoptosis Independently of the Bcl-2 Homolog CED-9. Genes Dev. 21, 3181-3194. doi:10.1101/gad.1607007

Sekiya, T., and Zaret, K. S. (2007). Repression by Groucho/TLE/Grg Proteins: Genomic Site Recruitment Generates Compacted Chromatin In Vitro and Impairs Activator Binding In Vivo. Mol. Cel 28, 291-303. doi:10.1016/ j.molcel.2007.10.002

Sellak, H., Wu, S., and Lincoln, T. M. (2012). KLF4 and SOX9 Transcription Factors Antagonize $\beta$-catenin and Inhibit TCF-Activity in Cancer Cells. Biochim. Biophys. Acta 1823, 1666-1675. doi:10.1016/ j.bbamcr.2012.06.027

Selvadurai, H. J., and Mason, J. O. (2011). Wnt/ $\beta$-catenin Signalling Is Active in a Highly Dynamic Pattern During Development of the Mouse Cerebellum. PLoS One 6, e23012. doi:10.1371/journal.pone.0023012

Sena, E., Bou-Rouphael, J., Rocques, N., Carron-Homo, C., and Durand, B. C. (2020). Mcl1 Protein Levels and Caspase-7 Executioner Protease Control Axial Organizer Cells Survival. Dev. Dyn. 249, 847-866. doi:10.1002/ dvdy. 169

Sena, E., Feistel, K., and Durand, B. C. (2016). An Evolutionarily Conserved Network Mediates Development of the Zona Limitans Intrathalamica, A Sonic Hedgehog-Secreting Caudal Forebrain Signaling Center. J. Dev. Biol. 4, 31. doi:10.3390/jdb4040031

Sena, E., Rocques, N., Borday, C., Amin, H. S. M., Parain, K., Sitbon, D., et al. (2019). Barhl2 Maintains T-Cell Factors as Repressors, and Thereby Switches off the Wnt $/ \beta$-Catenin Response Driving Spemann Organizer Formation. Development 146, dev 173112. doi:10.1242/dev.173112

Session, A. M., Uno, Y., Kwon, T., Chapman, J. A., Toyoda, A., Takahashi, S., et al. (2016). Genome Evolution in the Allotetraploid Frog Xenopus laevis. Nature 538, 336-343. doi:10.1038/nature19840

Shetty, P., Lo, M. C., Robertson, S. M., and Lin, R. (2005). C. elegans TCF Protein, POP-1, Converts from Repressor to Activator as a Result of Wnt-Induced 
Lowering of Nuclear Levels. Dev. Biol. 285, 584-592. doi:10.1016/ j.ydbio.2005.07.008

Shimogori, T., VanSant, J., Paik, E., and Grove, E. A. (2004). Members of the Wnt, $\mathrm{Fz}$, and Frp Gene Families Expressed in Postnatal Mouse Cerebral Cortex. J. Comp. Neurol. 473, 496-510. doi:10.1002/cne.20135

S. Hoppler and R. T. Moon (Editors) (2014). Wnt Signaling in Development and Disease: Molecular Mechanisms and Biological Functions (Hoboken, NJ: Wiley Blackwell).

Shy, B. R., Wu, C. I., Khramtsova, G. F., Zhang, J. Y., Olopade, O. I., Goss, K. H., et al. (2013). Regulation of Tcf7l1 DNA Binding and Protein Stability as Principal Mechanisms of Wnt/ $\beta$-Catenin Signaling. Cel Rep 4, 1-9. doi:10.1016/j.celrep.2013.06.001

Sinner, D., Kordich, J. J., Spence, J. R., Opoka, R., Rankin, S., Lin, S.-C. J., et al. (2007). Sox17 and Sox4 Differentially Regulate $\beta$-Catenin/T-Cell Factor Activity and Proliferation of Colon Carcinoma Cells. Mol. Cel Biol 27, 7802-7815. doi:10.1128/MCB.02179-06

Smith, S. T., and Jaynes, J. B. (1996). A Conserved Region of Engrailed, Shared Among All En-, Gsc-, Nk1-, Nk2- and Msh-Class Homeoproteins, Mediates Active Transcriptional Repression In Vivo. Development 122, 3141-3150. doi:10.1242/dev.122.10.3141

Söderholm, S., and Cantù, C. (2021). The WNT/ $\beta$-catenin Dependent Transcription: A Tissue-specific Business. WIREs Mech. Dis. 13, el511. doi:10.1002/wsbm.1511

Sokol, S., Christian, J. L., Moon, R. T., and Melton, D. A. (1991). Injected Wnt RNA Induces a Complete Body Axis in Xenopus Embryos. Cell 67, 741-752. doi:10.1016/0092-8674(91)90069-B

Sokol, S. Y. (2011). Maintaining Embryonic Stem Cell Pluripotency with Wnt Signaling. Development 138, 4341-4350. doi:10.1242/dev.066209

Spemann, H., and Mangold, H. (1924). über Induktion von Embryonalanlagen durch Implantation artfremder Organisatoren. Archiv für mikroskopische Anatomie und Entwicklungsmechanik 100, 599-638. doi:10.1007/BF02108133

Standley, H. J., Destrée, O., Kofron, M., Wylie, C., and Heasman, J. (2006). Maternal XTcf1 and XTcf4 Have Distinct Roles in Regulating Wnt Target Genes. Dev. Biol. 289, 318-328. doi:10.1016/j.ydbio.2005.10.012

Staudt, N., and Houart, C. (2007). The Prethalamus Is Established during Gastrulation and Influences Diencephalic Regionalization. Plos Biol. 5, e69. doi:10.1371/journal.pbio.0050069

Stern, C. D. (2002). Induction and Initial Patterning of the Nervous System - the Chick Embryo Enters the Scene. Curr. Opin. Genet. Dev. 12, 447-451. doi:10.1016/S0959-437X(02)00324-6

Stevens, M. L., Chaturvedi, P., Rankin, S. A., Macdonald, M., Jagannathan, S., Yukawa, M., et al. (2017). Genomic Integration of Wnt/ $\beta$-Catenin and BMP/ Smad1 Signaling Coordinates Foregut and Hindgut Transcriptional Programs. Development 144, 1283-1295. doi:10.1242/dev.145789

Sulston, J. E., Schierenberg, E., White, J. G., and Thomson, J. N. (1983). The Embryonic Cell Lineage of the Nematode Caenorhabditis elegans. Dev. Biol. 100, 64-119. doi:10.1016/0012-1606(83)90201-4

Tabar, V., and Studer, L. (2014). Pluripotent Stem Cells in Regenerative Medicine: Challenges and Recent Progress. Nat. Rev. Genet. 15, 82-92. doi:10.1038/ nrg3563

Taelman, V. F., Dobrowolski, R., Plouhinec, J. L., Fuentealba, L. C., Vorwald, P. P., Gumper, I., et al. (2010). Wnt Signaling Requires Sequestration of Glycogen Synthase Kinase 3 inside Multivesicular Endosomes. Cell. 143, 1136-1148. doi:10.1016/j.cell.2010.11.034

Tam, W.-L., Lim, C. Y., Han, J., Zhang, J., Ang, Y.-S., Ng, H.-H., et al. (2008). T-cell Factor 3 Regulates Embryonic Stem Cell Pluripotency and Self-Renewal by the Transcriptional Control of Multiple Lineage Pathways. Stem Cells 26, 2019-2031. doi:10.1634/stemcells.2007-1115

ten Berge, D., Kurek, D., Blauwkamp, T., Koole, W., Maas, A., Eroglu, E., et al. (2011). Embryonic Stem Cells Require Wnt Proteins to Prevent Differentiation to Epiblast Stem Cells. Nat. Cel Biol. 13, 1070-1075. doi:10.1038/ncb2314

Teratani-Ota, Y., Yamamizu, K., Piao, Y., Sharova, L., Amano, M., Yu, H., et al. (2016). Induction of Specific Neuron Types by Overexpression of Single Transcription Factors. In Vitro Cel Dev Biol Anim. 52, 961-973. doi:10.1007/s11626-016-0056-7

Thomas, K. R., and Capecchi, M. R. (1990). Targeted Disruption of the Murine Int1 Proto-Oncogene Resulting in Severe Abnormalities in Midbrain and Cerebellar Development. Nature 346, 847-850. doi:10.1038/346847a0
Thorpe, C. J., Schlesinger, A., Carter, J. C., and Bowerman, B. (1997). Wnt Signaling Polarizes an Early C. elegans Blastomere to Distinguish Endoderm from Mesoderm. Cell 90, 695-705. doi:10.1016/S00928674(00)80530-9

Topol, L., Chen, W., Song, H., Day, T. F., and Yang, Y. (2009). Sox9 Inhibits Wnt Signaling by Promoting $\beta$-Catenin Phosphorylation in the Nucleus. J. Biol. Chem. 284, 3323-3333. doi:10.1074/jbc.M808048200

Travis, A., Amsterdam, A., Belanger, C., and Grosschedl, R. (1991). LEF-1, a Gene Encoding a Lymphoid-specific Protein with an HMG Domain, Regulates T-Cell Receptor Alpha Enhancer Function [corrected]. Genes Dev. 5, 880-894. doi:10.1101/gad.5.5.880

Tsuji, S., and Hashimoto, C. (2005). Choice of Either Beta-Catenin or Groucho/ TLE as a Co-factor for Xtcf-3 Determines Dorsal-Ventral Cell Fate of Diencephalon during Xenopus Development. Dev. Genes Evol. 215, 275-284. doi:10.1007/s00427-005-0474-0

Turki-Judeh, W., and Courey, A. J. (2012). Groucho: A Corepressor with Instructive Roles in Development. Curr. Top. Dev. Biol. 98, 65-96. doi:10.1016/B978-0-12-386499-4.00003-3

Valenta, T., Lukas, J., and Korinek, V. (2003). HMG Box Transcription Factor TCF-4's Interaction with CtBP1 Controls the Expression of the Wnt Target Axin2/Conductin in Human Embryonic Kidney Cells. Nucleic Acids Res. 31, 2369-2380. doi:10.1093/nar/gkg346

Valentine, S. A., Chen, G., Shandala, T., Fernandez, J., Mische, S., Saint, R., et al. (1998). Dorsal-mediated Repression Requires the Formation of a Multiprotein Repression Complex at the Ventral Silencer. Mol. Cel Biol. 18, 6584-6594. doi:10.1128/MCB.18.11.6584

van Amerongen, R., and Nusse, R. (2009). Towards an Integrated View of Wnt Signaling in Development. Development 136, 3205-3214. doi:10.1242/ dev. 033910

van Beest, M., Dooijes, D., van de Wetering, M., Kjaerulff, S., Bonvin, A., Nielsen, O., et al. (2000). Sequence-specific High Mobility Group Box Factors Recognize 10-12-Base Pair Minor Groove Motifs. J. Biol. Chem. 275, 27266-27273. doi:10.1016/S0021-9258(19)61506-1

van de Wetering, M., Cavallo, R., Dooijes, D., van Beest, M., van Es, J., Loureiro, J., et al. (1997). Armadillo Coactivates Transcription Driven by the Product of the Drosophila Segment Polarity Gene dTCF. Cell 88, 789-799. doi:10.1016/S00928674(00)81925-X

van de Wetering, M., Oosterwegel, M., Dooijes, D., and Clevers, H. (1991). Identification and Cloning of TCF-1, a T Lymphocyte-specific Transcription Factor Containing a Sequence-specific HMG Box. EMBO J. 10, 123-132. doi:10.1002/j.1460-2075.1991.tb07928.x

van Genderen, C., Okamura, R. M., Farinas, I., Quo, R.-G., Parslow, T. G., Bruhn, L., et al. (1994). Development of Several Organs That Require Inductive Epithelial-Mesenchymal Interactions Is Impaired in LEF-1-Deficient Mice. Genes Dev. 8, 2691-2703.

Veien, E. S., Grierson, M. J., Saund, R. S., and Dorsky, R. I. (2005). Expression Pattern of Zebrafish Tcf7 Suggests Unexplored Domains of Wnt/beta-Catenin Activity. Dev. Dyn. 233, 233-239. doi:10.1002/dvdy.20330

Vermeulen, L., De Sousa E Melo, F., van der Heijden, M., Cameron, K., de Jong, J. H., Borovski, T., et al. (2010). Wnt Activity Defines Colon Cancer Stem Cells and Is Regulated by the Microenvironment. Nat. Cel Biol. 12, 468-476. doi:10.1038/ncb2048

Vieira, C., and Martinez, S. (2006). Sonic Hedgehog from the Basal Plate and the Zona Limitans Intrathalamica Exhibits Differential Activity on Diencephalic Molecular Regionalization and Nuclear Structure. Neuroscience 143, 129-140. doi:10.1016/j.neuroscience.2006.08.032

Walcher, L., Kistenmacher, A. K., Suo, H., Kitte, R., Dluczek, S., Strauß, A., et al. (2020). Cancer Stem Cells-Origins and Biomarkers: Perspectives for Targeted Personalized Therapies. Front. Immunol. 11, 1280. doi:10.3389/ fimmu.2020.01280

Wang, J., Garancher, A., Ramaswamy, V., and Wechsler-Reya, R. J. (2018). Medulloblastoma: From Molecular Subgroups to Molecular Targeted Therapies. Annu. Rev. Neurosci. 41, 207-232. doi:10.1146/annurev-neuro070815-013838

Wang, W., Wang, Y. G., Reginato, A. M., Glotzer, D. J., Fukai, N., Plotkina, S., et al. (2004). Groucho Homologue Grg5 Interacts with the Transcription Factor Runx2-Cbfa1 and Modulates its Activity during Postnatal Growth in Mice. Dev. Biol. 270, 364-381. doi:10.1016/j.ydbio.2004.03.003 
Wang, Y., He, L., Du, Y., Zhu, P., Huang, G., Luo, J., et al. (2015). The Long Noncoding RNA lncTCF7 Promotes Self-Renewal of Human Liver Cancer Stem Cells Through Activation of Wnt Signaling. Cell Stem Cell. 16, 413-425. doi:10.1016/j.stem.2015.03.003

Wessely, O., and De Robertis, E. M. (2002). Neural Plate Patterning by Secreted Signals. Neuron. 33, 489-491. doi:10.1016/s0896-6273(02)00596-2

Wiese, K. E., Nusse, R., and van Amerongen, R. (2018). Wnt Signalling: Conquering Complexity. Development. 145, dev165902. doi:10.1242/ dev. 165902

Williams, R. L., Hilton, D. J., Pease, S., Willson, T. A., Stewart, C. L., Gearing, D. P., et al. (1988). Myeloid Leukaemia Inhibitory Factor Maintains the Developmental Potential of Embryonic Stem Cells. Nature. 336, 684-687. doi:10.1038/336684a0

Wills, A. E., and Baker, J. C. (2015). E2a Is Necessary for Smad2/3-dependent Transcription and the Direct Repression of Lefty During Gastrulation. Dev. Cel. 32, 345-357. doi:10.1016/j.devcel.2014.11.034

Wilson, S. W., and Houart, C. (2004). Early Steps in the Development of the Forebrain. Develop. Cel. 6, 167-181. doi:10.1016/S1534-5807(04)00027-9

Wizeman, J. W., Guo, Q., Wilion, E. M., and Li, J. Y. (2019). Specification of Diverse Cell Types during Early Neurogenesis of the Mouse Cerebellum. Elife. 8, e42388. doi:10.7554/eLife.42388

Wray, J., and Hartmann, C. (2012). WNTing Embryonic Stem Cells. Trends Cel Biol. 22, 159-168. doi:10.1016/j.tcb.2011.11.004

Wray, J., Kalkan, T., Gomez-Lopez, S., Eckardt, D., Cook, A., Kemler, R., et al. (2011). Inhibition of Glycogen Synthase Kinase-3 Alleviates Tcf3 Repression of the Pluripotency Network and Increases Embryonic Stem Cell Resistance to Differentiation. Nat. Cel Biol. 13, 838-845. doi:10.1038/ncb2267

Xia, Z., Guo, M., and Ma, H. (2011). Functional Analysis of Novel Phosphorylation Sites of CREB-Binding Protein Using Mass Spectrometry and Mammalian Two-Hybrid Assays. Proteomics 11, 3444-3451. doi:10.1002/pmic.201100121

Yaklichkin, S., Vekker, A., Stayrook, S., Lewis, M., and Kessler, D. S. (2007). Prevalence of the EH1 Groucho Interaction Motif in the Metazoan Fox Family of Transcriptional Regulators. BMC Genomics. 8, 201. doi:10.1186/1471-2164-8-201

Yamamizu, K., Sharov, A. A., Piao, Y., Amano, M., Yu, H., Nishiyama, A., et al. (2016). Generation and Gene Expression Profiling of 48 Transcription-FactorInducible Mouse Embryonic Stem Cell Lines. Sci. Rep. 6, 25667. doi:10.1038/ srep25667

Yang, S. H., Kalkan, T., Morrisroe, C., Smith, A., and Sharrocks, A. D. (2012). A Genome-wide RNAi Screen Reveals MAP Kinase Phosphatases as Key ERK Pathway Regulators During Embryonic Stem Cell Differentiation. Plos Genet. 8, e1003112. doi:10.1371/journal.pgen.1003112

Yao, Y., Minor, P. J., Zhao, Y. T., Jeong, Y., Pani, A. M., King, A. N., et al. (2016). Cis-regulatory Architecture of a Brain Signaling Center Predates the Origin of Chordates. Nat. Genet. 48, 575-580. doi:10.1038/ng.3542

Yasuoka, Y., Suzuki, Y., Takahashi, S., Someya, H., Sudou, N., Haramoto, Y., et al. (2014). Occupancy of Tissue-specific Cis-Regulatory Modules by Otx2 and TLE/Groucho for Embryonic Head Specification. Nat. Commun. 5, 4322. doi:10.1038/ncomms5322

Ye, S., Zhang, T., Tong, C., Zhou, X., He, K., Ban, Q., et al. (2017). Depletion of Tcf3 and Lef1 Maintains Mouse Embryonic Stem Cell Self-Renewal. Biol. Open, bio. 6, 511-517. doi:10.1242/bio.022426
Yeung, J., Ha, T. J., Swanson, D. J., Choi, K., Tong, Y., and Goldowitz, D. (2014) Wls Provides a New Compartmental View of the Rhombic Lip in Mouse Cerebellar Development. J. Neurosci. 34, 12527-12537. doi:10.1523/ JNEUROSCI.1330-14.2014

Yi, F., Pereira, L., Hoffman, J. A., Shy, B. R., Yuen, C. M., Liu, D. R., et al. (2011). Opposing Effects of Tcf3 and Tcf1 Control Wnt Stimulation of Embryonic Stem Cell Self-Renewal. Nat. Cel Biol. 13, 762-770. doi:10.1038/ncb2283

Ying, Q. L., Nichols, J., Chambers, I., and Smith, A. (2003). BMP Induction of Id Proteins Suppresses Differentiation and Sustains Embryonic Stem Cell SelfRenewal in Collaboration with STAT3. Cell. 115, 281-292. doi:10.1016/S00928674(03)00847-X

Ying, Q. L., Wray, J., Nichols, J., Batlle-Morera, L., Doble, B., Woodgett, J., et al. (2008). The Ground State of Embryonic Stem Cell Self-Renewal. Nature. 453, 519-523. doi:10.1038/nature06968

Young, R. M., Ewan, K. B., Ferrer, V. P., Allende, M. L., Godovac-Zimmermann, J., Dale, T. C., et al. (2019). Developmentally Regulated Tcf7l2 Splice Variants Mediate Transcriptional Repressor Functions During Eye Formation. Elife. 8 , e51447. doi:10.7554/eLife.51447

Zeng, L., Fagotto, F., Zhang, T., Hsu, W., Vasicek, T. J., Perry, W. L., et al. (1997). The Mouse Fused Locus Encodes Axin, an Inhibitor of the Wnt Signaling Pathway that Regulates Embryonic Axis Formation. Cell. 90, 181-192. doi:10.1016/S0092-8674(00)80324-4

Zhan, T., Rindtorff, N., and Boutros, M. (2017). Wnt Signaling in Cancer. Oncogene. 36, 1461-1473. doi:10.1038/onc.2016.304

Zhang, X., Peterson, K. A., Liu, X. S., McMahon, A. P., and Ohba, S. (2013). Gene Regulatory Networks Mediating Canonical Wnt Signal-Directed Control of Pluripotency and Differentiation in Embryo Stem Cells. Stem Cells. 31, 2667-2679. doi:10.1002/stem.1371

Zhang, Y., and Wang, X. (2020). Targeting the Wnt/ $\beta$-Catenin Signaling Pathway in Cancer. J. Hematol. Oncol. 13, 165. doi:10.1186/s13045-020-00990-3

Žídek, R., Machoň, O., and Kozmik, Z. (2018). Wnt/ $\beta$-catenin Signalling Is Necessary for Gut Differentiation in a Marine Annelid, Platynereis Dumerilii. EvoDevo. 9, 14. doi:10.1186/s13227-018-0100-7

Conflict of Interest: The authors declare that the research was conducted in the absence of any commercial or financial relationships that could be construed as a potential conflict of interest.

Publisher's Note: All claims expressed in this article are solely those of the authors and do not necessarily represent those of their affiliated organizations, or those of the publisher, the editors and the reviewers. Any product that may be evaluated in this article, or claim that may be made by its manufacturer, is not guaranteed or endorsed by the publisher.

Copyright (c) 2021 Bou-Rouphael and Durand. This is an open-access article distributed under the terms of the Creative Commons Attribution License (CC $B Y$ ). The use, distribution or reproduction in other forums is permitted, provided the original author(s) and the copyright owner(s) are credited and that the original publication in this journal is cited, in accordance with accepted academic practice. No use, distribution or reproduction is permitted which does not comply with these terms. 